\title{
Castanhal (PA): entre a dinâmica metropolitana e a centralidade sub-regional de uma cidade média
}

\author{
Márcio Douglas Brito Amaral ${ }^{1}$ e Willame de Oliveira Ribeiro ${ }^{2}$
}

\footnotetext{
1 Professor Adjunto III do Instituto de Filosofia e Ciências Humanas da Universidade Federal do Pará; Professor do Programa de Pós-Graduação em Geografia, Brasil. E-mail: marcioamaral@ufpa.br

2 Geógrafo, Doutorando em Geografia pela Universidade Estadual Paulista/Presidente Prudente. Professor Assistente II da Universidade do Estado do Pará, Brasil. E-mail: willame.geo@gmail.com
}

RESUM 0: 0 principal objetivo desse trabalho é analisar se as cidades de porte médio que estão territorialmente próximas à metrópole de Belém, especialmente Castanhal, desempenham papel de cidade média, servindo de centro sub-regional que dentre outras coisas promove a intermediação entre os pequenos núcleos urbanos e as metrópoles, ou se estão funcionalmente integradas a metrópole de Belém através de redes de proximidade relativa e relacional, de modo a configurar uma lógica de metropolização do espaço em que os processos são definidos muito mais por relações e por fluxos. Para isso, são trabalhados, a partir de dados documentais, especialmente, migrações pendulares (IBGE, 2000, 2010), as interações espaciais de Castanhal com Belém, buscando compreender a dimensão metropolitana da cidade. No segundo momento, são trabaIhados dados relativos ao comércio e aos serviços, as feiras, empresas do setor de abastecimento e "agrolojas" e a organização política das elites locais por meio de um observatório social, buscando evidenciar a condição de cidade média. A principal conclusão é a de que embora exista um projeto claro de incorporação, de fato e não apenas na norma/lei, de Castanhal à região metropolitana de Belém, pode-se dizer que ainda existe uma "autonomia relativa" desta cidade em relação à metrópole, bem como, não parece ser o interesse dos grupos econômicos locais que tal incorporação se consolide.

Palavras-chave: metropolização, cidade média, Castanhal (PA).

\section{Castanhal (PA): between metropolitan dynamics and sub-regional centrality of a midsize city}

ABSTRACT: The main purpose of this study is to analyze whether the medium-sized cities that are territorially close to the metropolis of Belém, especially Castanhal, play the role of midsize cities, serving as sub-regional centers that among other things promotes the intermediation between small urban centres and metropolitan areas, or if they are functionally integrated into the metropolis of Belém through networks of relative and relational proximity, in order to configure a logic of metropolization of the space in which the procedures are defined much more by relations and by workflows. For this reason, are worked, from documentary data, especially, commuting (IBGE, 2000, 2010), the spatial interactions of Castanhal with Belém, seeking to understand the metropolitan dimension of the city. In the second moment, are worked data relating to trade and services, fairs, supply companies and "agrolojas" and the political organization of the local elite through social observatory, seeking to highlight the condition of a midsize city. The main conclusion is that although there is a project of incorporation, a real one and not just in standard/law, from Castanhal to the metropolitan area of Belém, it can be said that still exist a "relative autonomy" from that city to the metropolis, as well as 
does not seem to be the interest of local economic groups that such incorporation is consolidated.

Keywords: metropolization, midsize city, Castanhal (PA).

\section{INTRODUÇÃO}

A preocupação central deste texto é analisar o papel de Castanhal dentro da rede urbana amazônica. Embora tenha sido recentemente incorporada à região metropolitana de Belém ${ }^{1}$, o que parece ter encerrado uma polêmica histórica - se ela se configura como cidade média ou se faz parte da região metropolitana de Belém -, não estamos suficientemente convencidos sobre a questão. Desse modo, para além da dimensão institucional, a questão que se coloca é se Castanhal pode ser definida como uma cidade média do Nordeste Paraense ou se deve ser entendida como uma cidade de porte médio pertencente à Região M etropolitana de Belém.

Ao discutir o reforço da urbanização concentrada e do primado metropolitano para realidade de Belém, Trindade Jr. (1998) aponta que é necessário pensar para além dos limites administrativos da região metropolitana, incorporando o espaço metropolitano. Desse modo, segundo o autor, deve-se considerar, de um lado, a sua grande periferia de expansão (municípios de Ananindeua, Marituba, Benevides, Santa Bárbara e Santa Izabel) e, de outro lado, a sua área de influência imediata (municípios de Barcarena e Castanhal), que apesar de dispersa, ainda guarda forte dependência das atividades, serviços e empregos oferecidos pela metrópole de Belém.

Em outro trabalho, Trindade Jr. e Pereira (2007) ao discutirem a reestruturação da rede urbana e a maior importância assumida pelas cidades médias na Amazônia, destacam que três cidades têm assumido o papel de centros sub-regionais na região em que estão inseridas: Marabá (sudeste paraense), Santarém (oeste paraense) e Castanhal (nordeste paraense). Dentre os argumentos arrolados em favor dessa centralidade urbana das cidades médias destacam os de natureza demográfica, econômica e política. Deve-se ressaltar o caráter específico de Castanhal nessa discussão, pois, se por um lado, os autores apontam uma "relativa autonomia" de Castanhal em relação à estrutura metropolitana de Belém, por outro lado, não deixam de chamar a atenção para a direta articulação existente tanto em função da intensidade dos fluxos, quanto das relações políticas mantidas entre os blocos políticos sediados na capital e aqueles de Castanhal.

A fim de resolver essa querela a respeito do papel de Castanhal na rede urbana regional, Alves (2012) questiona se é possível falar em centralidade sub-regional de Castanhal ou de sub-centralidade metropolitana de Belém. Sua resposta aponta para a segunda hipótese, destacando que o caráter de centralidade dado a Castanhal dentro do contexto sub-regional do nordeste paraense não é mais suficiente para enten-

\footnotetext{
${ }^{1}$ Castanhal integra a Região M etropolitana de Belém desde o ano de 2012, como pode ser observado nas linhas do Diário da Justiça do Tribunal de Justiça do Estado do Pará: TJ/PA - DIÁRIO DA JUSTIÇA - Edição no 5026/2012 - Segunda-Feira, 14 de M aio de 2012.
}

PRACS: Revista Eletrônica de Humanidades do Curso de Ciências Sociais da UNIFAP 
der a problemática espacial, uma vez que as dinâmicas dos fluxos têm mostrado muito mais a existência de uma unidade urbana metropolitana ampliada, fragmentada e dispersa.

Se por um lado concordamos com a hipótese de que não é suficiente para entender a problemática espacial considerar Castanhal apenas como centro sub-regional do Nordeste Paraense, por outro lado, também não estamos totalmente convencidos de que ela faz parte de uma unidade metropolitana ampliada, fragmentada e dispersa, a exemplo da metrópole de São Paulo, analisada por Lencioni (2008). Consideramos ser necessário discutir melhor esse aspecto para realidade amazônica, pois no caso paulista o que promove a configuração dessa forma metropolitana é a concentração e a centralização das atividades urbanas, principalmente, a indústria de alta tecnologia e inovação, os serviços avançados e o trabalho qualificado, aspecto contrastante com o quadro regional amazônico.

\section{A DINÂMICA METROPOLITANA E A CIDADE DE CASTANHAL}

\subsection{A metropolização e a dispersão metropolitana de Belém}

A discussão a respeito das realidades e das problemáticas associadas aos espaços urbanos tem marcado grande parte da produção acadêmica atual e muitos conceitos têm surgido enquanto instrumentos analíticos que visam uma melhor interpretação das novas e complexas realidades do mundo contemporâneo. A concepção de metropolização do espaço está inclusa neste contexto e possui sua natureza intrinsecamente associada ao processo de globalização, sendo, ao mesmo tempo, estruturada e estruturadora deste.

Os espaços metropolizados, de acordo com Lencioni (2013), não se restringem as fronteiras das regiões metropolitanas instituídas pelo Estado e não se confundem com a metrópole, possuem uma amplitude maior. Segundo esta autora, espaços metropolizados seriam aqueles que

[...] assumem aspectos e características similares, mesmo que em menor escala, aos da metrópole, quer dizendo respeito aos investimentos de capital, ao desenvolvimento das atividades de serviços com sua correlata concentração de trabalho imaterial; ou ainda, relacionados ao desenvolvimento das atividades de gestão e administração. Podem, também, apresentar outros aspectos, como a tendência ao desenvolvimento de vários centros comerciais e de serviços, a forma de consumir e viver semelhante a da metrópole, bem como uma densidade significativa de redes imateriais e a presença bastante visível dos socialmente excluídos (LENCIONI, 2013, p. 19).

Sendo assim, a metropolização, para esta autora, diz respeito a um processo bastante amplo, diretamente associado ao fenômeno da globalização e as suas consequências na modernização dos espaços, nas mudanças dos modos de vida e dos cos- 
tumes e nas reorientações das estratégias de reprodução do capital. Lencioni (2004, p. 154) fala do "[...] extravasamento da dinâmica metropolitana para outros territórios [...]" que, assim, "[...] não é mais exclusiva da metrópole ou da região metropolitana institucionalizada" (op. cit.). Neste sentido, Lencioni (2011) destaca que a metropolização do espaço "[...] nada mais é do que uma metamorfose do processo de urbanização" (p. 135), mais precisamente, uma fase superior da urbanização.

Esse entendimento permite reconhecer a metropolização em espaços fora das regiões metropolitanas ou mesmo em áreas não diretamente subordinadas à metrópole, mas que possuem outras dinâmicas de centralidade não metropolitanas, como no caso das cidades médias. É a partir dessa interpretação que a autora chega a seguinte percepção da realidade socioespacial atual:

0 que a paisagem revela, de fato, são mosaicos de espaços metropolizados confundidos com o de espaços ainda não metropolizados e na medida em que se vai distanciando das áreas de maior densidade de pessoas, mercadorias e fluxos, os espaços não metropolizados vão se impondo aos metropolizados (LENCIONI, 2013, p. 19).

Desse modo, fica clara a amplitude do entendimento da metropolização para a autora, que além de não restringi-lo às áreas metropolitanas, também reconhece no mesmo uma relevante dimensão cultural. Isso porque a metropolização viria acompanhada "[...] de uma alteração profunda da cultura mercantil, a qual atinge todas as esferas da vida e incide sobre espaços de toda ordem" (op. cit., p. 24). E é essa condição que fundamentaria a afirmação de que "[...] os hábitos culturais e os valores urbanos próprios da metrópole se difundem para além dela" (op. cit.), possibilitando que nas pequenas e médias cidades se reconheça hábitos e valores que antes eram exclusividade das áreas metropolitanas.

Contudo, esse entendimento da metropolização traz consigo um risco de distorção da realidade, qual seja, considerar os processos dinamizadores do espaço e estruturadores da rede urbana como originários apenas de espaços metropolitanos. Isso porque o termo metropolização se constitui a partir da concepção de metrópole, um tipo de espaço urbano, mas não o único. Numa rede urbana cada vez mais complexa a consideração das metrópoles como os únicos vetores de ação, mesmo que apenas da ação modernizadora, constitui a negação dessa complexidade, que está justamente na sobreposição de lógicas diversas, mediante a ação de sujeitos variados e situados em centros urbanos com papéis e posições hierárquicas variadas no interior da rede urbana.

Essa mesma preocupação é manifestada por Sposito (2015) ao analisar a concepção de metropolização do espaço de Lencioni, quando diz: "[...] procuro evitar que se adote a ideia de que as dinâmicas em curso são movimentos que se estabelecem, exclusivamente, como vetores originados nas metrópoles em propagação pelos demais espaços" (p. 139). Explica ainda que isso não foi dito nem escrito pela autora, 
mas que pode ser uma posição a se derivar de sua construção teórica. Para Sposito 0 processo maior vivenciado no mundo contemporâneo ainda é a urbanização.

Desse modo, apesar dos processos a que se refere o conceito de metropolização terem existência e importância quase inquestionável, o termo 'metropolização' traz consigo alguns inconvenientes, como bem elucida Sposito (op. cit.), o principal deles é a possibilidade de encobrir a importância de outros centros urbanos não metropolitanos no âmbito do processo de urbanização ou no interior da rede urbana.

Diante dessas constatações e do reconhecimento do poder explicativo que a ideia de metropolização possui na interpretação da realidade do Nordeste do Pará, especialmente, da cidade de Castanhal, lócus da presente pesquisa, se optou por considerar o processo de metropolização do espaço em uma perspectiva mais restrita, referindo-se basicamente a produção do espaço metropolitano. Nesse sentido, o resultado do processo de metropolização é a própria metrópole, ou seja, o processo de metropolização se refere ao movimento, às ações que contribuem à constituição do espaço metropolitano. Um movimento que não cessa quando a metrópole ganha existência, mas que a acompanha em seu constante processo de produção.

No caso de Belém, capital do Estado do Pará, o processo de metropolização que, na visão de Trindade Jr (1998), se inicia na década de 1960 e se consolida nas décadas seguintes, "pressupõe a incorporação de cidades e vilas próximas a Belém, definindo uma malha urbana única, ainda que fragmentada" (p. 3). Segundo este autor, o processo de metropolização de Belém é marcado por dois momentos distintos e que se revelam em duas formas diferenciadas: a forma urbana confinada e a forma urbana dispersa.

A primeira é caracterizada por uma expansão urbana restrita aos limites estabelecidos pelo denominado "cinturão institucional", que instalado no período da segunda guerra mundial, consistia num conjunto de instituições públicas localizado nos limites da cidade e que passou a funcionar como um obstáculo à expansão urbana horizontal contínua. A ocupação das baixadas, o adensamento populacional e a valorização dos terrenos de topografia mais elevada foram as grandes marcas dessa forma confinada (TRINDADE Jr, 1998).

Já a forma dispersa se estabelece a partir da superação da barreira formada pelo cinturão institucional nos anos 1960 e a expansão da malha urbana para "[...] localidades até então consideradas distantes, notadamente, para a Rodovia Augusto M ontenegro (eixo Belém-Icoaraci) e para a BR-316 (eixo Belém-Ananindeua) [...]" (TRINDADE Jr, 1998, p. 104). A década de 1980 consolida esses eixos de expansão e, por consequência, a forma urbana dispersa.

Os novos espaços de assentamento passaram a receber em grande escala a população pobre deslocada das áreas centrais, principalmente das baixadas, que passaram por um relevante processo de valorização a partir da realização de obras de saneamento. Com isso, esses novos espaços de assentamento distantes do centro da metrópole adquiriram um forte caráter de periferia urbana, não somente pela distância 
geométrica em relação ao centro da cidade, mas, como explicam Chaveiro e Anjos (2007) em relação à definição de periferia, por possuir "[...] um cotidiano específico, bem como uma modalidade de tempo social que define a vida dos sujeitos [...] um lugar específico de dramas sociais, de problemas e vicissitudes humanas" (p. 183).

Esse processo de produção de espaços periféricos, em muito, se confunde com 0 próprio processo de metropolização de Belém, funcionando esses espaços como verdadeiras 'cidade dormitórios', ou seja, espaços de moradia para a população de baixa renda, que trabalhando na área central de Belém precisa desenvolver um movimento pendular diário entre o espaço de trabalho e o espaço de moradia. Na atualidade, esse processo de metropolização assume novas feições, pois o movimento de dispersão não é composto exclusivamente pela população pobre, mas também por grupos de média e alta renda, atraídos, principalmente, pela oferta de novos produtos imobiliários sob o formato de condomínios fechados.

A Região M etropolitana de Belém - RMB foi institucionalizada em âmbito estadual em 19 de outubro de 1995, por força da Lei Complementar no 027, sendo formada pelos municípios de Belém, Ananindeua, Marituba, Benevides e Santa Bárbara (DIÁRIO OFICIAL DO ESTADO DO PARÁ, n. 28.116, de 22/12/95). Pela Lei Complementar no 072, de 20 de abril de 2010, publicada no DOE № 31.656, de 30/04/2010, foi inserido mais um município à RM $B$, Santa Izabel do Pará.

E pela Lei Complementar n. 076, de 28 de dezembro de 2011, que altera a Lei 027, de 19 de outubro de 1995 (DIÁRIO OFICIAL DO ESTADO DO PARÁ, 28 DE DEZEM BRO DE 2011, CADERNO 2, p. 8) o município de Castanhal também passa a integrar a RM B. Com isso a RM B passou a ser composta pelos municípios de Belém, Ananindeua, Marituba, Benevides, Santa Bárbara do Pará, Santa Isabel do Pará e Castanhal.

Castanhal é parte integrante do que neste trabalho se denomina Região Nordeste do Pará e possui com Belém uma relação diferente da tecida pelos demais centros urbanos do espaço metropolitano, uma vez que a formação e o crescimento de Castanhal não é resultado da dispersão dos espaços de assentamento da metrópole, não se constituindo a cidade enquanto periferia da RMB e nem mesmo como espaço de assentamento para as classes de média e alta renda vindas de Belém.

A própria inserção do município na RMB é questionável sobre certos aspectos, pois, como esclarece Fernandes, Bitoun e Araújo (2009), as definições no Brasil das regiões metropolitanas a partir das decisões dos Estados da federação têm sido marcadas pela imprecisão conceitual. Sendo, desse modo, muito comum a não coincidência da delimitação oficial da região metropolitana com a dinâmica e realidade de fato metropolitana.

Dessa forma, apesar de Castanhal, e também dos demais municípios do nordeste paraense, manter fortes relações com a Região Metropolitana de Belém, o que acaba sendo esperado, já que todo o território paraense é área de influência de sua capital; isso não chega a descaracterizar a diferenciação e a particularidade do nordeste pa- 
raense, que possui densidade técnica, econômica, populacional e de infraestrutura distintas da Região M etropolitana de Belém.

\subsection{0 nordeste paraense e a dispersão metropolitana}

O recorte espacial aqui denominado Região Nordeste do Estado do Pará (figura 01), não tem base em nenhuma regionalização oficial do Governo do Estado do Pará ou do Governo Federal do Brasil, mas foi estabelecido a partir da concepção da região enquanto estruturada/ estruturante por/de sua rede de cidades e tomou por base os dados do IBGE, no estudo Regiões de Influência das Cidades 2007 (IBGE, 2008), para 0 reconhecimento das centralidades e das áreas de influência dos centros urbanos.

A Região Nordeste do Pará abrange parte significativa do litoral paraense, estendendo-se, no sentido oeste-leste, do município de São João da Ponta ao município de Viseu e também parte da área interiorana denominada Região Bragantina, isto é, a área compreendida entre as cidades de Belém, capital do Estado do Pará e a cidade de Bragança. A extensão da Bragantina inclusa na Região Nordeste do Pará se estende de Castanhal às intermediações de Bragança e Viseu.

FIGURA 01: M apa de Região Nordeste do Pará delimitada a partir de sua rede urbana. 2007.

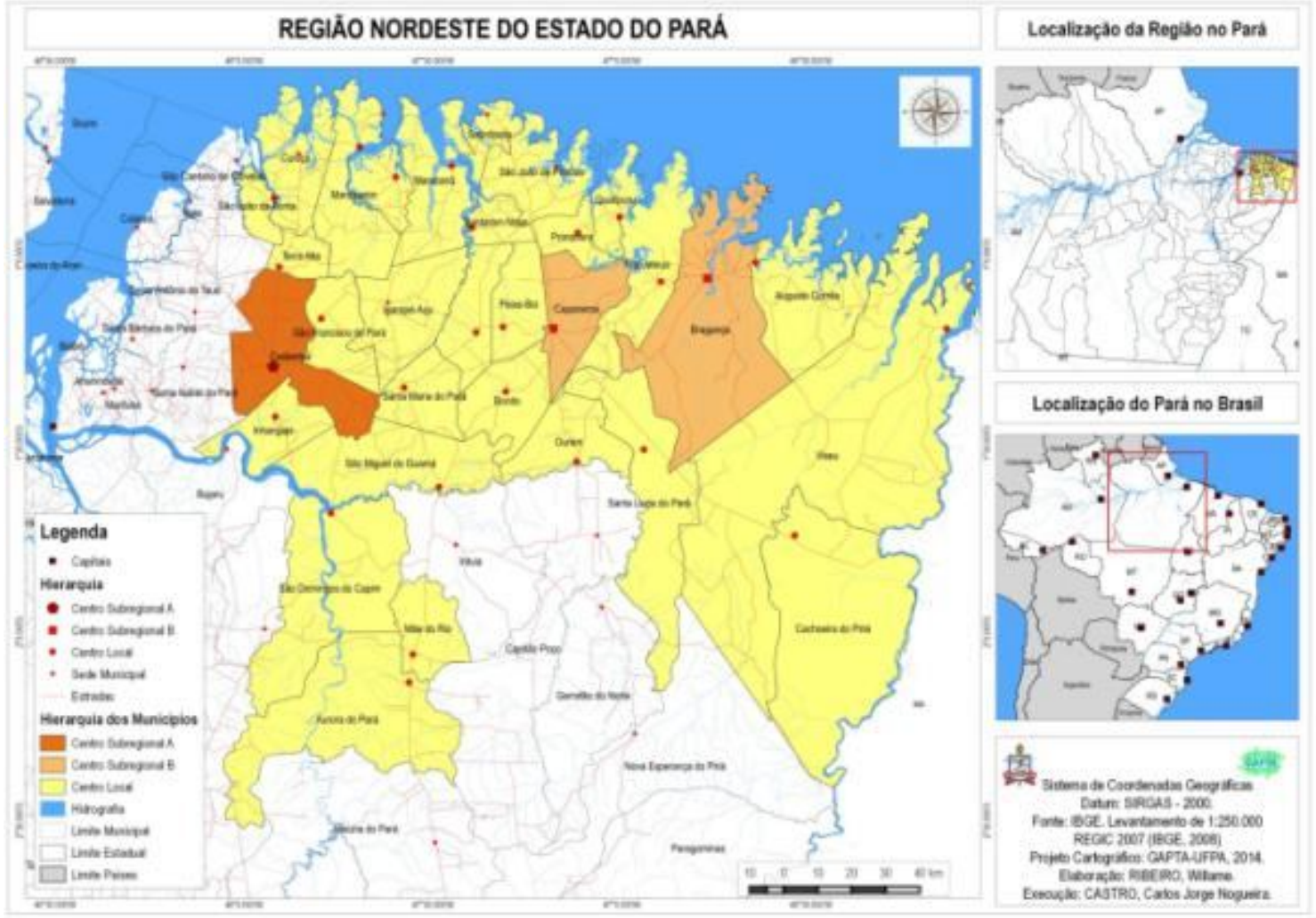

FONTE: Regiões de Influência das Cidades 2007 (IBGE, 2008).

ELABORAÇÃO: Willame de Oliveira Ribeiro. 
A região nordeste do Pará tem uma população total de 991.734 habitantes distribuídos em uma área de $28.656 \mathrm{~km}^{2}$ possuindo, desse modo, uma densidade em torno de 35 habitantes por $\mathrm{km}^{2}$, o que é bastante superior à média do Estado do Pará, que possui uma densidade de 6 hab./ $\mathrm{km}^{2}$ (IBGE, 2015). A gênese da colonização da região tem dois momentos principais. 0 primeiro remonta ao próprio processo de colonização da região amazônica no século XVII, quando foram estabelecidos os primeiros povoamentos litorâneos, como a atual cidade de Bragança; o segundo momento, e mais decisivo à estruturação da rede urbana e da região, ocorre no final do século XIX, por meio da colonização da chamada Região Bragantina, com vistas ao atendimento das necessidades criadas pelo desenvolvimento da economia da borracha na Amazônia.

Essa colonização teve como marcas principais a utilização dos migrantes nordestinos e a construção da Estrada de Ferro de Bragança - EFB. A ferrovia levou 25 anos para ser concluída, tendo início sua construção em 1883 e o término de sua construção apenas em 1908 (LEANDRO; SILVA, 2012). Seus 220 km de extensão ligavam Belém e Bragança e, portanto, cortavam o nordeste do Pará, contribuindo decisivamente para a estruturação dessa região. Com sua extinção pelo governo federal em 1965 esse papel estruturador da região passou a ser desempenhado pelas rodovias (SIQUEIRA, 2008).

A Região Nordeste do Pará, por sua proximidade com a RM B, passa a ser um espaço prioritário para a dispersão metropolitana de Belém, entretanto, esse processo se materializa envolvido por grande complexidade e a partir de determinados vetores, isto é, de forma parcial e incompleta. A cidade de Castanhal, por sua importância regional e pela proximidade com Belém, é a cidade mais atingida pela dispersão metropolitana, no contexto do nordeste paraense, entretanto, as marcas desse processo também podem ser verificadas nos demais centros de destaque da região, como as cidades de Bragança e Capanema.

Neste texto, o processo de dispersão metropolitana será considerado mais a partir de seus rebatimentos sobre a cidade de Castanhal, porém, antes de passar diretamente a essa análise, é importante entender as interações espaciais entre Castanhal e Belém e a realidade que se cria a partir disso e como o fenômeno da dispersão compõe esse quadro de interações.

\subsection{0 aprofundamento das interações espaciais entre Castanhal e Belém: a dimen- são metropolitana}

A análise das interações espaciais demonstra a posição bastante complexa desempenhada pela cidade de Castanhal, que, de um lado, desempenha o papel de principal centralidade do nordeste paraense, polarizando (como será apresentado mais adiante) uma grande quantidade de cidades e aproximando seu papel da concepção de cidade média; e, de outro lado, aumenta suas inter-relações com o espaço metro- 
politano de Belém, fazendo com que alguns estudos, como o de Alves (2012), a considerem uma subcentralidade metropolitana. Essas duas lógicas são fundamentais à compreensão da realidade e dos papéis desempenhados por Castanhal na rede urbana regional.

Neste momento, as atenções se voltam para esse segundo aspecto, o aprofundamento da condição metropolitana de Castanhal, evidenciando um importante processo de metropolização do espaço nesta cidade. A tentativa de compreender essa lógica se dá pela utilização da concepção de interações espaciais, que, na visão de Corrêa (1997, p. 279),

[...] constituem um amplo e complexo conjunto de deslocamentos de pessoas, mercadorias, capital e informação sobre o espaço geográfico. Podem apresentar maior ou menor intensidade, variar segundo a frequência de ocorrência e, conforme a distância e direção, caracterizar-se por diversos propósitos e se realizar através de diversos meios e velocidades.

A concepção de interações espaciais de Corrêa é bastante ampla, não apresentando restrição aos fluxos econômicos, mas abarcando dinâmicas essencialmente sociais, ao se referir aos deslocamentos de pessoas, cujas motivações podem ser as mais diversas, apesar do destaque de atividades como trabalho e estudo. Camagni (2005) expõe uma caracterização das interações espaciais bastante assemelhada à definição anteriormente enunciada.

Toda atividade localizada sobre o espaço físico, seja esta uma unidade de produção, uma unidade demográfica ou uma cidade, desenvolve com o entorno que a rodeia uma complexa rede de relações bidirecionais que tem lugar em múltiplos níveis. Por um lado, ao redor desta atividade se materializa um complexo campo de forças de atração, de irradiação, de repulsão, de cooperação que fornece, por assim dizer, a energia de base para o funcionamento (e mesmo a existência) do sistema territorial. Por outro lado, todas as atividades localizadas no entorno exercem, por sua vez, uma influência sobre o primeiro centro através dos canais mais diversos [...] (CAMAGNI, 2005, p. 79).

A caracterização de Camagni frisa o caráter bidirecional das relações, a partir da consideração de um ponto específico, que, ao mesmo tempo é emissor e receptor de uma ação, uma vez que o entorno, que recebe a primeira ação, não é passivo diante dela, mas atua gerando uma resposta ao primeiro centro, configurando a realidade da interação. Outro aspecto a ser salientado dessa passagem de Camagni (2005) é a importância que as interações espaciais possuem na estruturação do próprio espaço, ou do sistema territorial, como prefere o autor, considerando essas interações não como processos que se dão no espaço, mas como inerentes ao espaço, componentes de sua totalidade. 
Desse modo, as interações espaciais funcionam como um importante indicador ao reconhecimento do espaço metropolitano, normalmente marcado por grande intensidade de interações. Para o estudo das interações espaciais entre Castanhal e Belém se utilizaram os dados de migração pendular por motivo de trabalho e estudo para 0 ano 2000 (IBGE, 2000) e também de migração pendular por motivo de trabalho e de migração pendular por motivo de estudo, vistos separadamente no censo de 2010 (IBGE, 2010), como exposto no quadro 01.

0 primeiro elemento a se destacar é que as migrações pendulares entre Castanhal e Belém, tanto por trabalho quanto por estudo, tiveram grande crescimento entre 2000 e 2010. Se considerados conjuntamente os dados de trabalho e de estudo de 2010, se percebe que os deslocamentos de Castanhal para Belém aumentaram mais que o dobro, já os deslocamentos no sentido contrário, de Belém para Castanhal, tiveram uma elevação ainda mais expressiva, com uma quantidade quatro vezes maior, com largo destaque às migrações pendulares motivadas pelo trabalho.

QUADRO 01: Migração pendular por motivo de trabalho e estudo entre os municípios de Belém e Castanhal

\begin{tabular}{|c|c|c|}
\hline 2000 & DE BELÉM PARA CASTANHAL & DE CASTANHAL PARA BELÉM \\
\hline $\begin{array}{c}\text { (TRABALHO E ESTUDO) } \\
2010\end{array}$ & 309 & 900 \\
\hline $\begin{array}{c}\text { (TRABALHO) } \\
2010\end{array}$ & 946 & 1319 \\
\hline (ESTUDO) & 266 & 1130 \\
\hline
\end{tabular}

FONTE: IBGE (2000), IBGE (2010)

Mas em termos absolutos, os deslocamentos para Belém são muito mais expressivos, apesar de nos deslocamentos por trabalho em 2010 os números se aproximarem. De qualquer forma, no que importa para a presente análise, fica evidente a rápida ampliação das relações entre Castanhal e Belém, demonstrando, assim, uma tendência à incorporação de Castanhal ao contexto metropolitano.

Entretanto, a intensidade de deslocamentos entre Belém e Castanhal é muito menor que a existente entre Belém e os principais municípios de sua região metropolitana. A tabela 01 apresenta os principais municípios de origem de migrantes pendulares que se destinavam a Belém em 2010. Visando evidenciar os fluxos mais significativos, foram considerados apenas os que possuíam número igual ou maior que 200 migrantes e foi gerado um outro indicador, o Índice de Intensidade da M igração Pendular por Trabalho - I.I.M.P.T., que consiste na divisão do número de migrantes pendulares por trabalho pela população total do município de origem em 2010, multiplicado por 1000. Com isso se obtém a relativização da intensidade do fluxo de acordo com o contingente populacional do município de origem.

Analisando a tabela 01 é possível observar que os municípios de Ananindeua, Marituba e Benevides possuem, tanto em quantidade absoluta de migrantes quanto em relação à intensidade do fluxo, números muito mais expressivos que os demais. 0 
primeiro com 65.621 migrantes e 139 de I.I.M .P.T., o segundo com 10.879 migrantes e 101 de I.I.M.P.T. e o terceiro com 3.827 migrantes e 74 I.I.M.P.T. Na figura 02, onde o fluxo de pessoas por motivo de trabalho originado nesses municípios e destinado a Belém é representado por linhas mais escuras e espessas, indicando a maior intensidade das interações; é possível observar que estes são justamente os municípios mais próximos de Belém. Ananindeua e Marituba, inclusive, conurbados com Belém e Benevides, em processo de conurbação.

TABELA 01: Migração pendular por motivo de trabalho com destino ao M unicípio de Belém/PA em 2010

\begin{tabular}{lcccc}
\hline & MUNICíPIO DE ORIGEM* & $\begin{array}{c}\text { QUANTIDADE DE } \\
\text { M IGRANTES }\end{array}$ & $\begin{array}{c}\text { POPULAÇÃO DO MUNICIPIO } \\
\text { DE ORIGEM }\end{array}$ & I.I.M.P.T.** \\
\hline $\mathbf{1}$ & Ananindeua & 65621 & 471.980 & 139 \\
$\mathbf{2}$ & Marituba & 10879 & 108.246 & 101 \\
$\mathbf{3}$ & Benevides & 3827 & 51.651 & 74 \\
$\mathbf{4}$ & Santa Bárbara do Pará & 761 & 17.141 & 44 \\
$\mathbf{5}$ & Santo Antônio do Tauá & 596 & 26.674 & 22 \\
$\mathbf{6}$ & Santa Isabel do Pará & 1193 & 59.466 & 20 \\
$\mathbf{7}$ & Salinópolis & 319 & 37.421 & 9 \\
$\mathbf{8}$ & Vigia & 396 & 47.889 & 8 \\
$\mathbf{9}$ & Castanhal & 1319 & 173.149 & 8 \\
$\mathbf{1 0}$ & Igarapé-Açu & 218 & 35.887 & 6 \\
$\mathbf{1 1}$ & Barcarena & 606 & 99.859 & 6 \\
$\mathbf{1 2}$ & Abaetetuba & 758 & 141.100 & 5 \\
$\mathbf{1 3}$ & Igarapé-M iri & 305 & 58.077 & 5 \\
$\mathbf{1 4}$ & São M iguel do Guamá & 253 & 51.567 & 4 \\
$\mathbf{1 5}$ & Capanema & 225 & 63.639 & 2 \\
\hline $\mathbf{1 6}$ & Bragança & 281 & 113.227 & \\
\hline * Foram considerados apenas os municípios do Estado do Pará com 200 ou mais migrantes pendulares com destino a Be- \\
lém. \\
** İndice de Intensidade da Migração Pendular por Trabalho - alcançado a partir da divisão do número de migrantes pendu- \\
lares por trabalho pela população total do município de origem em 2010, multiplicado por 1000. \\
FONTE: IBGE (2010) & & &
\end{tabular}

Essa intensidade destacada da migração pendular por trabalho para Belém originada nesses municípios, confirma a profundidade da integração que eles possuem com Belém e a formação de uma estrutura urbana integrada de caráter metropolitano. Já os municípios que se seguem na intensidade da migração: Santa Bárbara do Pará, com 761 migrantes e 44 de I.I.M.P.T.; Santo Antônio do Tauá com 596 migrantes e 22 de I.I.M.P.T.; Santa Isabel do Pará, com 1193 migrantes e 20 de I.I.M.P.T.; Vigia, com 396 migrantes e 8 de I.I.M.P.T.; e Castanhal, com 1319 e também 8 de I.I.M.P.T.; ocupam uma situação intermediária, possuindo razoável integração com Belém e o espaço metropolitano, mas não o suficiente ao seu reconhecimento como integrantes desse espaço, isto é, estes municípios, pelos dados de migração pendular do trabalho para Belém, se caracterizam como centros urbanos com relações signifi- 
cativas com a metrópole e não como parte dela.

Como expõe a figura 02, esse conjunto de municípios, cujo fluxo de pessoas por motivo de trabalho para Belém é representado pelas linhas vermelhas, possui um maior distanciamento de Belém, em relação à Ananindeua, Marituba e Benevides, entretanto, constitui um entorno metropolitano com importantes relações com a metrópole. Salinas, que aparece tanto na tabela 01 quanto na figura 02, ocupando a posição de sétimo município na intensidade de emissão de migrantes pendulares por trabalho para Belém; não foi citado no texto por possuir uma relação muito diferente dos demais com Belém, pois sendo um importante balneário regional e, principalmente, para a população de Belém, a cidade expressa um forte processo de metropolização do espaço, na forma considerada por Lencioni (2013), mas marcada por grande sazonalidade. Isto é, as interações espaciais de Salinas com Belém são bem menos contínuas e estáveis no tempo do que as constituídas pelos outros municípios citados nesse movimento.

FIGURA 02: M apa representando as migrações pendulares por motivo de trabalho com destino à Belém. 2010.

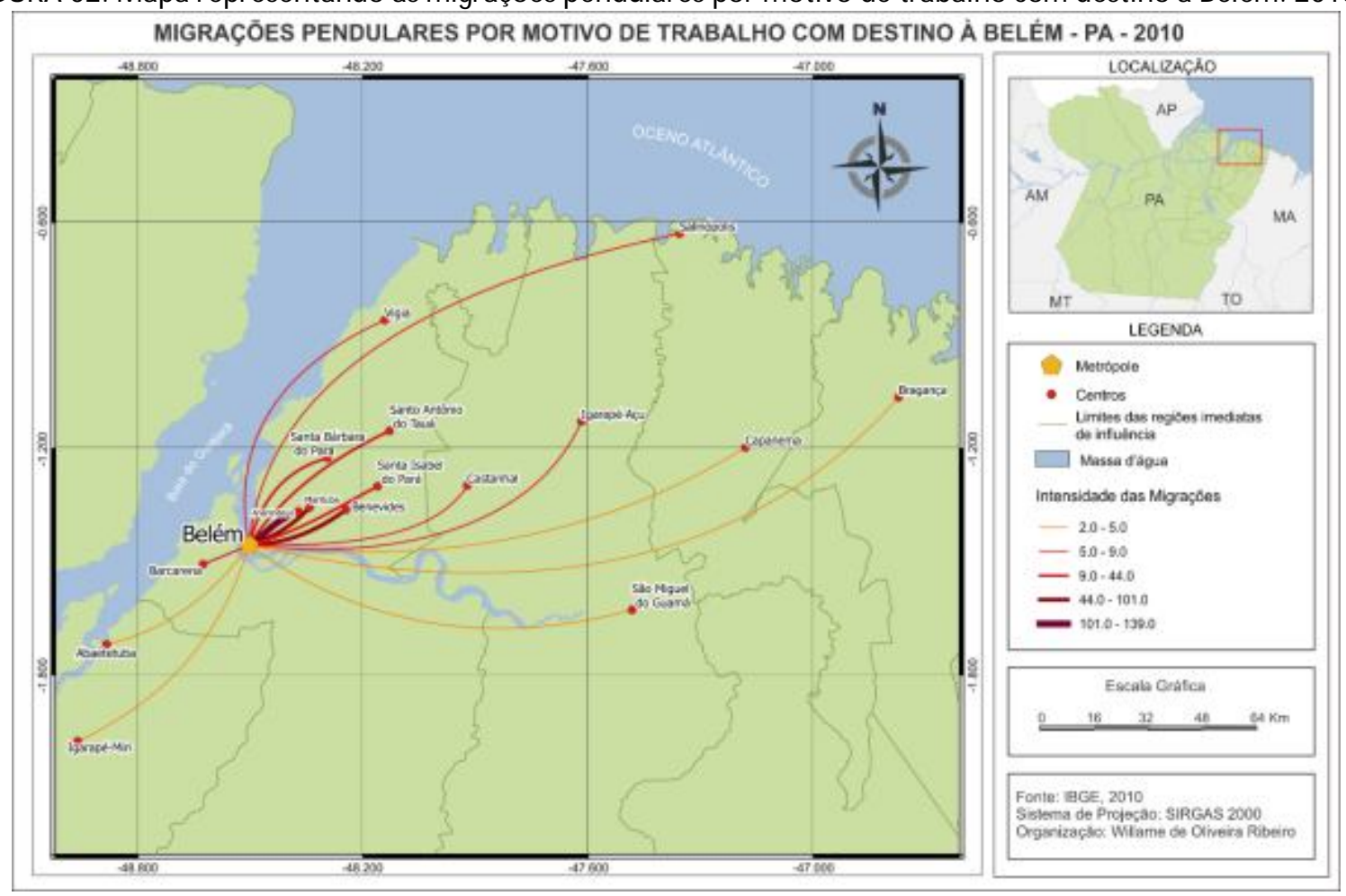

FONTE: IBGE (2010).

ELABORAÇÃO: Willame de Oliveira Ribeiro.

Os demais municípios presentes na tabela 01 e figura 02, da posição 10 a 16, são originadores de contingentes de migração pendular por trabalho com intensidade muito mais reduzida, indicando, portanto, um maior distanciamento da realidade metropolitana. Entre esses estão Capanema e Bragança, os dois outros centros de expressão regional no Nordeste Paraense. 
TABELA 02: Migração pendular por motivo de estudo com destino ao M unicípio de Belém/PA em 2010

MUNICÍPIO DE ORIGEM*

QUANTIDADE DE

MIGRANTES

\begin{tabular}{|lcccc}
\hline $\mathbf{1}$ & Ananindeua & 22745 & 471.980 & 48 \\
\hline $\mathbf{2}$ & Benevides & 1156 & 51.651 & 22 \\
\hline $\mathbf{3}$ & Marituba & 2235 & 108.246 & 21 \\
\hline $\mathbf{4}$ & Barcarena & 1125 & 99.859 & 11 \\
\hline $\mathbf{5}$ & Santo Antônio do Tauá & 248 & 26.674 & 9 \\
\hline $\mathbf{6}$ & Santa Isabel do Pará & 470 & 59.466 & 8 \\
\hline $\mathbf{7}$ & Castanhal & 1130 & 173.149 & 7 \\
\hline $\mathbf{8}$ & Vigia & 274 & 47.889 & 6 \\
\hline $\mathbf{9}$ & Abaetetuba & 486 & 141.100 & 3 \\
\hline $\mathbf{1 0}$ & Capanema & 210 & 63.639 & 3 \\
\hline $\mathbf{1 1}$ & Paragominas & 206 & 97.819 & 2 \\
\hline $\mathbf{1 2}$ & Tucuruí & 201 & 97.128 & 2 \\
\hline $\mathbf{1 3}$ & Bragança & 206 & 113.227 & 2 \\
\hline $\mathbf{1 4}$ & Cametá & 215 & 120.896 & 1 \\
\hline $\mathbf{1 5}$ & Marabá & 234 & 233.669 & 2 \\
\hline
\end{tabular}

* Foram considerados apenas os municípios do Estado do Pará com 200 ou mais migrantes pendulares por motivo de estudo com destino a Belém.

** Índice de Intensidade da M igração Pendular por Estudo - alcançado a partir da divisão do número de migrantes pendulares por estudo pela população total do município de origem em 2010, multiplicado por 1000.

FONTE: IBGE (2010)

A tabela 02 e a figura 03 evidenciam uma intensidade bastante destacada de Ananindeua, Benevides e Marituba enquanto origem de migrantes pendulares por motivo de estudo para Belém. 0 primeiro com 22.745 migrantes e 48 de Índice de Intensidade da M igração Pendular por Estudo - I.I.M .P.E.; o segundo com 1.156 migrantes e 22 de I.I.M.P.E.; e o terceiro com 2.235 e 21 de I.I.M.P.E. Desse modo, as migrações pendulares por estudo para Belém, no mesmo sentido que as migrações por trabalho, expressam a característica de espaço metropolitano para o conjunto desses três municípios acrescidos de Belém. Ananindeua, Benevides e M arituba possuem interações com Belém, nessa variável de estudos, muito mais intensas que qualquer outro município, por isso a cor mais escura e espessa na figura 03.

Um segundo nível de intensidade desses migrantes para Belém é formado por Barcarena, Santo Antônio do Tauá, Santa Isabel do Pará, Castanhal e Vigia, com números absolutos de 274 a 1125 migrantes pendulares por estudo e I.I.M.P.E. de 6 a 11. Esse segundo grupo, identificado com a linha de cor vermelha na figura 03, por esse critério, compõe o entorno metropolitano, isto é, os espaços que não possuem características metropolitanas claras, mas que são atingidos pelo processo de dispersão metropolitana e acabam por constituir uma relação bastante estreita com o espaço metropolitano, especialmente com o seu núcleo, Belém. 
FIGURA 03: M apa representando as migrações pendulares por motivo de estudo com destino à Belém. 2010.

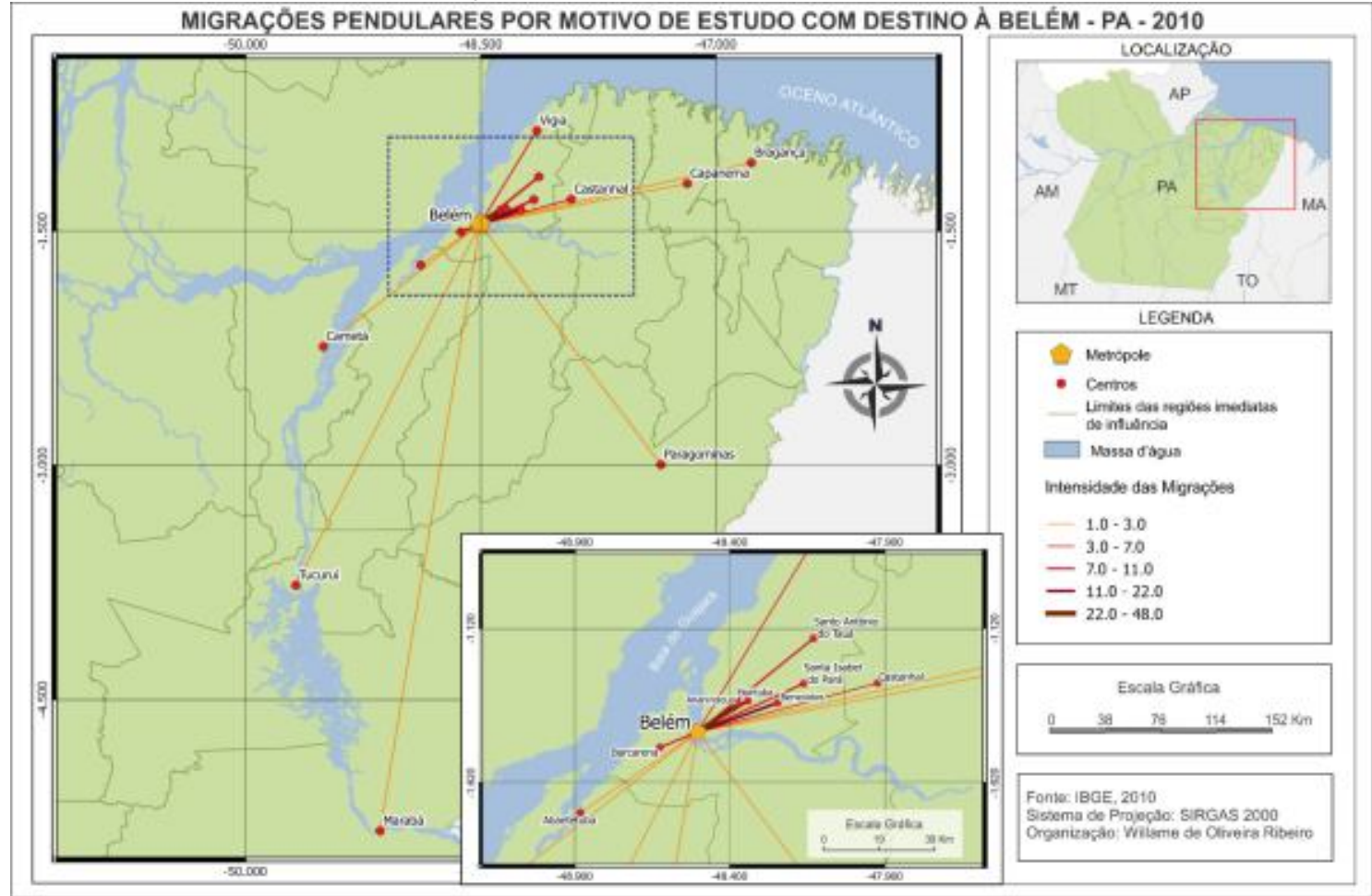

FONTE: IBGE (2010).

ELABORAÇÃO: Willame de Oliveira Ribeiro.

Já os municípios que ocupam as últimas colocações na ordem de intensidade da tabela 02, Abaetetuba, Capanema, Paragominas, Tucuruí, Bragança, Cametá e M arabá; e que se encontram representados pelas linhas de cor laranja na figura 03, possuem número de migrantes pendulares para Belém variando de 234, para 0 caso de Marabá, a 486, número de migrantes com origem em Abaetetuba. 0 índice de intensidade da migração pendular por estudo - I.I.M.P.E., por sua vez, varia de 1, Marabá, a 3, Abaetetuba. Esse último grupo, apesar de manter relações importantes com Belém, como atestam os dados, possui um distanciamento bem maior que os municípios que compõem os dois primeiros conjuntos, o que acaba refletindo num número menor de migrantes por estudo para Belém.

Por isso, aqui se considera esse último conjunto como não pertencendo à cidaderegião de Belém, forma aqui considerada mais adequada para entender a inserção regional de Belém, já que, do ponto de vista de um espaço relacional, entre esses municípios e a metrópole já se nota um abrandamento das interações espaciais.

Levando em consideração que Belém estruturou um espaço metropolitano mais conciso, envolvendo outros municípios, e também um outro espaço mais amplo, no entorno, com interações fortes com o núcleo metropolitano e que inclui não apenas centros locais mas também outros centros de expressão regional; optou-se pela utilização do conceito de cidade-região (M AGALHÃES, 2008; DELGADO, 2003; LENCIONI, 2006) enquanto ferramenta teórica mais coerente para se interpretar essa realidade. 
Partindo da compreensão de Haesbaert (2010) a respeito da necessidade de integrar os princípios da homogeneidade ou da coesão, que enfatiza a diferenciação espacial, e o princípio da integração regional ou da articulação, que privilegia as interações e as ações dos sujeitos na geração de fluxos, enquanto fundamentais a uma nova proposição para o conceito de região; é possível atestar a configuração do espaço metropolitano envolvendo Belém, Ananindeua, Marituba e Benevides.

Já o entorno metropolitano, que inclui Barcarena, Santo Antônio do Tauá, Santa Isabel do Pará, Vigia, Santa Bárbara do Pará, Santa Isabel do Pará e Castanhal reúne centros com uma natureza bastante diversa daqueles que compõem o espaço metropolitano. A maior parte desse centros estão na categoria de centros locais, de acordo com IBGE (2008), à exceção de Vigia, caracterizado como centro de zona B, por polarizar um centro local, São Caetano de Odivelas; e de Castanhal, classificado na hierarquia urbana como centro sub-regional A, polarizando 12 centros locais. Castanhal, inclusive, é fundamental ao reconhecimento da cidade-região de Belém, já que o conceito exige a existência de outros centros com expressão regional.

Desse modo, considera-se aqui que Belém constitui uma cidade-região, que possui dois espaços distintos, o espaço metropolitano e o entorno metropolitano. Castanhal compõe essa segunda dimensão. E é justamente isso que torna complexo os papéis desempenhados pela cidade de Castanhal, que apesar de possuir uma densidade de interações com Belém, apresenta números bem mais modestos do que aqueles registrados no interior do espaço metropolitano. Desse modo, o caráter metropolitano de Castanhal precisa ser relativizado, o que se torna mais evidente ainda quando se considera o processo de dispersão metropolitana.

\section{CASTANHAL: A PRODUÇÃO DA CIDADE E A CENTRALIDADE SUB-REGIONAL}

Ainda buscando responder a questão principal da pesquisa, procurou-se investigar, empiricamente, algumas dinâmicas econômicas e políticas responsáveis pela centralidade sub-regional de Castanhal. Assim, foram analisados o comércio e os serviços, as feiras, os empreendimentos do setor de abastecimento e as "agrolojas", bem como uma organização representante dos interesses das elites locais (o Observatório Social de Castanhal). Para isso, foram realizadas coletas de dados sistemáticos, por meio de entrevistas gravadas, junto aos responsáveis pelos empreendimentos e aos representantes de instituições públicas e privadas da cidade; da análise documental, principalmente do material fornecido pelas instituições; e de observações de campo, com verificação de fluxos de mercadorias e pessoas, registros fotográficos e coleta de coordenadas geográficas na área pesquisada.

\subsection{0 comércio e os serviços em Castanhal}

Tomando como ponto de partida a espacialidade do comércio e dos serviços (Figu- 
ra 04) em Castanhal, pode-se afirmar que a cidade apresenta um centro principal de localização dessas atividades, o que a torna uma cidade mononucleada em consideração as referidas atividades. Essa área principal de comércio e serviços corresponde aos principais eixos de circulação rodoviária da cidade, sendo-os: a Avenida Barão do Rio Branco (antiga via ferroviária - Estrada de Ferro de Bragança) e a Avenida Presidente Vargas (Rodovia BR-316). A partir de dados coletados pode-se dizer que a maior intensidade de localização das referidas atividades encontra-se no quadrante entre as avenidas Presidente Vargas (BR-316) e Comandante Assis, bem como entre as avenidas Lauro Sodré e a 10 de M aio, no bairro Centro.

A Avenida Barão do Rio Branco concentra a maior complexidade em termos comerciais, encontrando-se na mesma desde o comércio de pequeno porte até 0 de grande porte, com a presença de capitais local, regional, nacional e internacional, haja vista a presença de empresas de capital aberto de sociedade anônima sendo filiais de grupos atuantes nacionalmente. Esta área apresenta essencialmente comércio varejista com expressiva presença da comercialização de produtos como: calçados, confecções, departamento, aviamentos, papelaria, entre outros. Além disso, apresenta a forte presença de serviços, tanto públicos quanto privados, destacando-se a presença de órgãos da gestão municipal e a concentração bancária.

FIGURA 04: Carta-Imagem de Castanhal. Concentração de comércio e serviços nas adjacências das Avenidas Barão do rio Branco e Presidente Vargas. 2009.

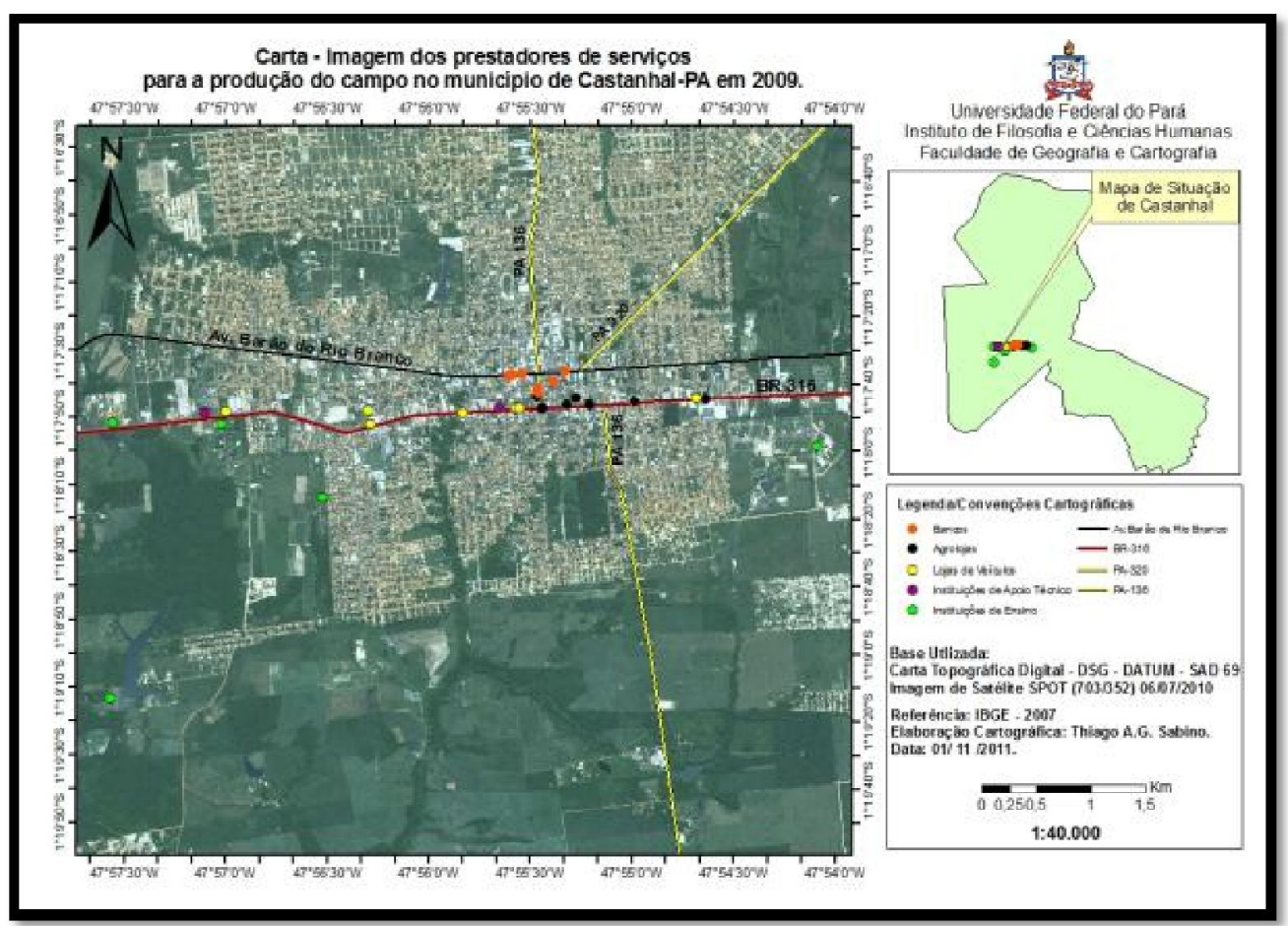

FONTE: Trabalho de campo, 2011.

A Avenida Presidente Vargas, correspondente a BR-316 dentro dos limites do município de Castanhal, apresenta uma concentração de atividades comerciais e de ser- 
viços em sua maioria diferenciadas da tipologia anteriormente apresentada na Avenida Barão do Rio Branco. Na Avenida Presidente Vargas destaca-se a presença de lojas de autopeças, ligados aos serviços automotores, lojas voltadas ao atendimento das demandas do campo, bem como empreendimentos de autosserviço, que atende particularmente ao público da metrópole de Belém em viagem para ao litoral (praias conhecidas como Salinas, Algodoal, Marudá, Crispim, Ajuruteua etc.). Como exemplo deste último tipo pode-se citar o Yamada Plaza, um empreendimento que se destaca dentro do setor comercial e de serviços, tanto por ser um dos poucos empreendimentos de grande porte presentes em Castanhal, quanto por ofertar serviços atualmente não observados na realidade da cidade, como, por exemplo, cinema e praça de alimentação.

Além desse centro principal de comércio e serviços, é possível encontrar em Castanhal, alguns novos espaços que mais recentemente passam a ofertar essa atividade: as vias paralelas e transversais ao quadrante entre as Avenidas Presidente Vargas e Comandante Assis, em que se detecta o desenvolvimento de novos corredores comerciais e de serviços; e alguns grandes bairros da cidade, tais como, Jaderlândia, Novo Olinda, Milagre e lanetama. Nessas novas áreas destacam-se a presença de farmácias, filiais menores de lojas de departamento, panificadoras, mercantis, serviços especializados de saúde, serviços de educação, dentre outros.

No segundo momento da análise do comércio e dos serviços em Castanhal, procurou-se investigar as redes de relações por elas tecidas. Assim, foi possível perceber que essas atividades presentes na cidade apresentam duas lógicas e reforçam dois processos geográficos. A primeira refere-se à presença de empreendimentos nacionais e regionais dentro da cidade que reforçam a dinâmica da modernização da cidade, o que acaba por inserir Castanhal, em parte, na lógica da metropolização do espaço, tanto a partir de Belém, principalmente por empresas que tradicionalmente atuam na região metropolitana (Grupo Líder, Grupo Y. Yamada, Lojas Visão, Farmácia Big Bem etc.), quanto de outros espaços metropolitanos nacionais de onde se dispersam grandes empreendimentos do comércio varejista como, por exemplo, Lojas Americanas.

O segundo faz alusão à presença de empreendimentos, locais e regionais, que não resultam e não reforçam a dinâmica metropolitana de Belém dentro da cidade, configurando relações horizontais, em que Castanhal aparece como centro de uma região, e relações verticais, em que essa cidade se relaciona com dinâmicas provenientes de outras regiões do país, principalmente, o Nordeste. São empresas que atuam em Castanhal e que acabam por reforçar dinâmicas e lógicas não metropolitanas, destacando-se os estabelecimentos comerciais denominados de Meio a Meio ou "Atacarejo", mas também empreendimentos modernos ligados a grupos familiares da cidade e cuja rede de relações se faz com a região Nordeste do Brasil, como Grupo Ibaraki, Lojas Radisco e Lojas Marilar. 
A partir da análise desses dados do comércio e dos serviços de Castanhal pode-se considerar que se, por um lado, a presença das grandes redes varejistas de Belém promove a modernização da paisagem e evidencia aspectos da metropolização do espaço e, portanto, se estrutura enquanto um relevante vetor de dispersão metropolitana, por outro lado, não se pode negar a permanência da força dos empreendimentos locais que procuram resistir à competição dos grupos exógenos e manter fortes relações horizontais, particularmente, com o Nordeste do Estado do Pará, relativamente independentes da metrópole.

\subsection{A relação cidade e campo em Castanhal}

Um dos aspectos mais reveladores da "centralidade urbana" de Castanhal pode ser encontrado na relação cidade e campo. Esta pode ser entendida a partir de duas referências de análise: as feiras e as empresas de abastecimento; e os serviços voltados para o campo, principalmente das agrolojas. Antes de falar sobre cada um deles, ressalta-se que esses dois elementos, da forma como estão desenhados, em nada reforçam a dinâmica da dispersão metropolitana de Belém, principalmente, porquê esta metrópole não tem estabelecido uma capacidade centralizadora neste aspecto. Desse modo, pode-se afirmar muito mais a presença de uma centralidade sub-regional de Castanhal, do que uma sub-centralidade de Belém, contrariando o que aponta Alves (2012) a partir de outras variáveis ${ }^{2}$.

No que tange aos serviços voltados para o campo, destacam-se em Castanhal a presença de agrolojas - empresas voltadas ao atendimento das demandas de produtos para o campo, tais como, sementes, implementos agrícolas, pesticidas, herbicidas, vacinas, roupas estilo country, botas, chapéus etc. - e as instituições de ensino e pesquisa voltadas para atender essas demandas específicas do campo.

No quadro 03 é possível verificar a presença das agrolojas em Castanhal, destacando-se as atividades que desenvolvem, ano de instalação, número de funcionários, abrangência de vendas, principais fornecedores etc. Dentre os aspectos presentes neste quadro destacam-se: o predomínio de empresas locais, pequenas e pouco modernas no controle deste setor. Aspecto que ajuda a reforçar o caráter não metropolitano do controle dessa atividade, uma vez que, a maioria das lojas não possui filiais $(66,66 \%)$, não tem telefone fixo $(55,55 \%)$ e internet $(77,77 \%)$; a presença de uma rede de fornecedores de produtos comercializados em que se destacam as cidades das regiões sudeste (São Paulo, São Bernardo do Campo, Rio Claro), centro-oeste (Goiânia), sul (Santa M aria), nordeste (Fortaleza) e Norte (Paragominas, Santa Izabel e Barcarena). Ressalte-se a ausência da metrópole de Belém na rede de relações; a área de abrangência das vendas, em que predomina, basicamente, o nordeste paraense, se-

\footnotetext{
${ }^{2}$ Por mais que usemos o termo contrariando, gostaríamos de deixar claro que também consideramos a possibilidade de ampliação da centralidade de Belém, no que se configura como uma possível cidade região em termos amazônicos, a partir da incorporação de novas funções metropolitanas.
}

PRACS: Revista Eletrônica de Humanidades do Curso de Ciências Sociais da UNIFAP 
guida de algumas áreas de abrangência menor, do oeste do M aranhão (a baixada maranhense), do Amapá, do sudeste (Marabá) e do oeste do Pará (Santarém).

QUADRO 03: Castanhal. Principais agrolojas. 2014.

\begin{tabular}{|c|c|c|c|c|c|c|c|c|c|c|}
\hline Empresa & $\begin{array}{l}\text { Grupo } \\
\text { per- } \\
\text { ten- } \\
\text { cen- } \\
\text { te }\end{array}$ & Tipo de comércio & $\begin{array}{l}\text { Ano } \\
\text { de } \\
\text { insta- } \\
\text { lação }\end{array}$ & $\begin{array}{l}\text { Fun- } \\
\text { cioná- } \\
\text { rios }\end{array}$ & $\begin{array}{l}\text { Área de abrangência } \\
\text { das vendas }\end{array}$ & $\begin{array}{l}\text { Principais forne- } \\
\text { cedores }\end{array}$ & $\begin{array}{l}\text { Pos } \\
\text { sui } \\
\text { fili- } \\
\text { al }\end{array}$ & $\begin{array}{l}\text { Possi } \\
\text { de } \\
\text { Tel i } \\
\text { ef } t \\
\text { on } \\
\text { e }\end{array}$ & $\begin{array}{l}\text { ibilid } \\
\text { com } \\
\text { in } r \\
\text { te } \\
\text { rn } \\
\text { et } t\end{array}$ & $\begin{array}{l}\text { dades } \\
\text { npra } \\
\text { repre } \\
\text { pre- } \\
\text { sen- } \\
\text { tante }\end{array}$ \\
\hline Agriterra & Local & $\begin{array}{l}\text { Fertilizantes, semen- } \\
\text { tes em gerais, mate- } \\
\text { riais agrícola. }\end{array}$ & 1986 & 05 & $\begin{array}{l}\text { Castanhal, Santa Ma- } \\
\text { ria, Concórdia do Pará, } \\
\text { Tomé Açú, Igarapé } \\
\text { Açu, Curuçá, Capitão } \\
\text { Poço. }\end{array}$ & $\begin{array}{l}\text { Fertilizantes de } \\
\text { Barcarena, semen- } \\
\text { tes em gerais de } \\
\text { São Paulo e outros } \\
\text { materiais agrícolas } \\
\text { de Goiânia, Goiás. }\end{array}$ & Não & $\operatorname{Sim} N$ & |ão & Não \\
\hline Agronorte & Local & $\begin{array}{l}\text { Sementes forragei- } \\
\text { ras, fertilizantes agrí- } \\
\text { colas, máquinas e im- } \\
\text { plementos agrícolas. }\end{array}$ & 1998 & 08 & $\begin{array}{l}\text { Castanhal, M ãe do Rio, } \\
\text { Irituia, Igarapé Açu. }\end{array}$ & $\begin{array}{l}\text { São Paulo e Ceará } \\
\text { (compra de calcá- } \\
\text { rio). }\end{array}$ & Não & $\operatorname{Sim} N$ & |ão & Não \\
\hline Agropará & Local & $\begin{array}{l}\text { Produtos veterinários } \\
\text { e pet shop. }\end{array}$ & 2007 & 03 & $\begin{array}{l}\text { Castanhal, São Domin- } \\
\text { gos do Capim, São } \\
\text { M iguel do Guamá, São } \\
\text { Francisco do Pará }\end{array}$ & $\begin{array}{l}\text { São Paulo e Goia- } \\
\text { nia (Goiás). }\end{array}$ & Não & Não Si & im & Não \\
\hline $\begin{array}{l}\text { Agrosho- } \\
\text { ping }\end{array}$ & Local & $\begin{array}{l}\text { Ração para animais } \\
\text { de pequenos e gran- } \\
\text { de portes e medica- } \\
\text { mentos veterinários. }\end{array}$ & 2000 & 06 & Castanhal e Capanema & $\begin{array}{l}\text { Medicamentos da } \\
\text { marca VALE E TOR- } \\
\text { TUGA vem de ou- } \\
\text { tros estados do sul } \\
\text { e sudeste do País. }\end{array}$ & Não & NãolN & |ão & Não \\
\hline Agrossales & Local & $\begin{array}{l}\text { Ração para animais } \\
\text { de pequenos e gran- } \\
\text { de portes e medica- } \\
\text { mentos veterinários. }\end{array}$ & 1992 & 08 & $\begin{array}{l}\text { Castanhal, São Miguel, } \\
\text { Santa Maria e Inhan- } \\
\text { gapi. }\end{array}$ & São Paulo e Goiás. & Não & NãoN & |ão & Não \\
\hline Casmape & Local & $\begin{array}{l}\text { Diferentes máquinas } \\
\text { agrícolas tais como: } \\
\text { roçadeiras, motor } \\
\text { bomba, motor diesel, } \\
\text { grupo geradores, la- } \\
\text { vadora de alta pres- } \\
\text { são, além dos pulve- } \\
\text { rizadores manuais e } \\
\text { motorizados, vendas } \\
\text { e assistência técnica. }\end{array}$ & 2002 & 40 & $\begin{array}{l}\text { Castanhal todos os } \\
\text { demais municípios que } \\
\text { compõem a região } \\
\text { nordeste do Pará e } \\
\text { também os estados do } \\
\text { Maranhão e Amapá. }\end{array}$ & Still e Yamaha & Não & NãoN & |ão & Sim \\
\hline Dinagro & Local & $\begin{array}{l}\text { Defensivos agrícolas, } \\
\text { adubos, irrigação e } \\
\text { sementes. }\end{array}$ & 1996 & 05 & $\begin{array}{l}\text { Castanhal. Santa Ma- } \\
\text { ria, Capitão Poço, Ca- } \\
\text { panema, M oju, Santa } \\
\text { Izabel, Mãe do Rio, } \\
\text { Bragança, Traquateua, } \\
\text { Santo Antônio do Tauá. }\end{array}$ & $\begin{array}{l}\text { Ceará: Fortaleza, } \\
\text { São Paulo e Alago- } \\
\text { as. }\end{array}$ & Sim & NãoN & Jão & Não \\
\hline $\begin{array}{l}\text { Grupo } \\
\text { Gasparim }\end{array}$ & Local & $\begin{array}{l}\text { Sementes para pas- } \\
\text { tagem, emprementos } \\
\text { agrícolas, suplemen- } \\
\text { to mineral e outros } \\
\text { produtos agropecuá- } \\
\text { rios. }\end{array}$ & 2011 & $\begin{array}{l}\text { Não } \\
\text { infor- } \\
\text { mado }\end{array}$ & $\begin{array}{l}\text { Castanhal, Tomé Açu, } \\
\text { Capanema, Peixe Boi, } \\
\text { Marabá, Santarém e } \\
\text { Paragominas. }\end{array}$ & $\begin{array}{l}\text { São Paulo: } \text { São } \\
\text { Bernardo e Rio } \\
\text { Claro e Rio Grande } \\
\text { do Sul: Santa Maria }\end{array}$ & Sim & $\operatorname{Sim} N$ & Jão & Não \\
\hline $\begin{array}{l}\text { Monte } \\
\text { Verde }\end{array}$ & Local & $\begin{array}{l}\text { Adubos, defensivos } \\
\text { agrícolas, rações, pet } \\
\text { shop, sal mineral, }\end{array}$ & 2011 & 03 & $\begin{array}{l}\text { Castanhal, Igarapé } \\
\text { Açu, Curuçá e Mara- } \\
\text { panim. }\end{array}$ & $\begin{array}{l}\text { Paragominas, São } \\
\text { Paulo, Goiás (Goiâ- } \\
\text { nia). }\end{array}$ & Não & NãoN & Jão & Não \\
\hline
\end{tabular}




\begin{tabular}{|c|c|c|c|c|c|c|c|c|}
\hline & & ferragens em geral. & & & & & & \\
\hline Propec & Local & $\begin{array}{l}\text { Equipamentos agrí- } \\
\text { colas, medicamentos, } \\
\text { vestuários, ração, sal } \\
\text { mineral }\end{array}$ & 1987 & $\begin{array}{l}\text { Castanhal, Capanema, } \\
\text { Bragança, Capitão Po- } \\
\text { ço, Irituia, Mãe do Rio, } \\
\text { Garrafão do Norte, } \\
\text { Nova Esperança do Pi- } \\
\text { riá, Ourém, Concórdia } \\
\text { do Pará, Tomé-Açu e } \\
\text { Tailândia. }\end{array}$ & $\begin{array}{l}\text { São Paulo, Nordes- } \\
\text { te do Brasil, Goiás, } \\
\text { e Pará, com desta- } \\
\text { que para Santa } \\
\text { lzabel do Pará, } \\
\text { com a ração para- } \\
\text { ense. }\end{array}$ & Sim & Sim Sim & Sim \\
\hline
\end{tabular}

FONTE: Trabalho de Campo (2014). Org. Emerson Gil Santos Corrêa.

Quanto às feiras de Castanhal, como se nota na figura 05, as feiras e os empreendimentos do setor de abastecimento estão concentrados numa área específica da cidade. Na verdade, a distribuição espacial dessas atividades acompanha de perto a organização das demais atividades de comércio e serviços nela existentes, o que denota seu caráter de monocentralidade. Assim, pode-se dizer que em Castanhal, uma parcela significativa da população da cidade e da região tem como principal alternativa de abastecimento, fora do circuito dos supermercados e hipermercados: a Feira do Produtor Rural, o Mercado Central Abdias Bezerra, o Mercado Municipal Antônio Barros Maciel, a Fort Fruit, o Verdurão Furacão Negro, a Castanhal Super Frutas e a Center Fruit.

FIGURA 05: Castanhal: Localização das feiras e mercados no interior da cidade.

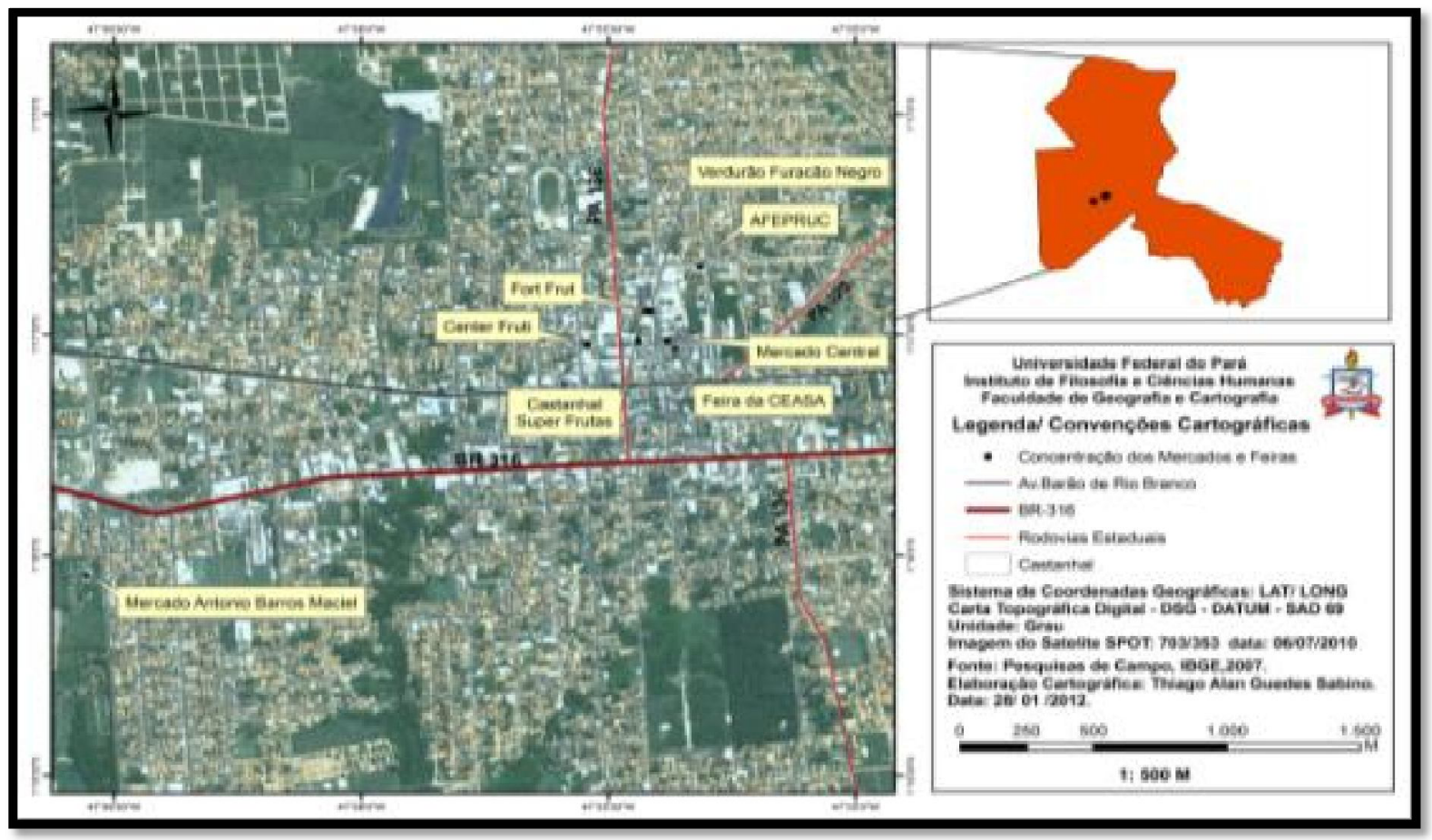

FONTE: Trabalho de campo, outubro de 2012.

Em Castanhal foi possível desenhar a rede de proximidade territorial e a rede de proximidade relativa (LENCIONI, 2006) da cidade tomando como referência, de um 
lado, o processo de abastecimento das feiras, mercados e empresas do setor de abastecimento e, de outro lado, o processo de distribuição desses produtos no interior da cidade e da região.

Em termos da rede de proximidade territorial elegemos como referência a Feira do Produtor Rural de Castanhal, bem como sua associação (AFEPRUC - Associação Feira do Produtor Rural de Castanhal), pois ela consegue fazer a articulação da cidade com as colônias agrícolas/agrovilas do próprio município, bem como com as cidades do entorno.

Por meio da figura 06 é possível visualizar mais de perto essa rede de proximidade de Castanhal. É interessante notar que se trata de uma área bem servida de infraestrutura rodoviária, inclusive com asfaltamento, o que facilita esse escoamento da produção até a cidade de Castanhal que, por sua vez, se localiza num entroncamento de várias rodovias: no sentido norte, articulando os municípios de Terra Alta, São João da Ponta, Curuçá e Marapanim, tem-se a PA-136 e a PA-318; no sentido sul, fazendo a ligação com Inhangapi, tem-se a PA-036; no sentido oeste, em direção a capital do estado, tem-se a BR-316 em que se destaca a relação com Santa Izabel do Pará; na direção da antiga estrada de ferro Belém-Bragança, sentido nordeste, na PA-320, tem-se a forte ligação com os municípios de São Francisco do Pará e Igarapé-Açu; na direção leste, seguindo a BR-316 e a BR-010, bem como a PA-124 e PA-253, tem-se os municípios de Santa M aria do Pará, São M iguel do Guamá, Ourém, Capitão Poço etc.

\section{FIGURA 06: M apa representando a rede de proximidade territorial de Castanhal}

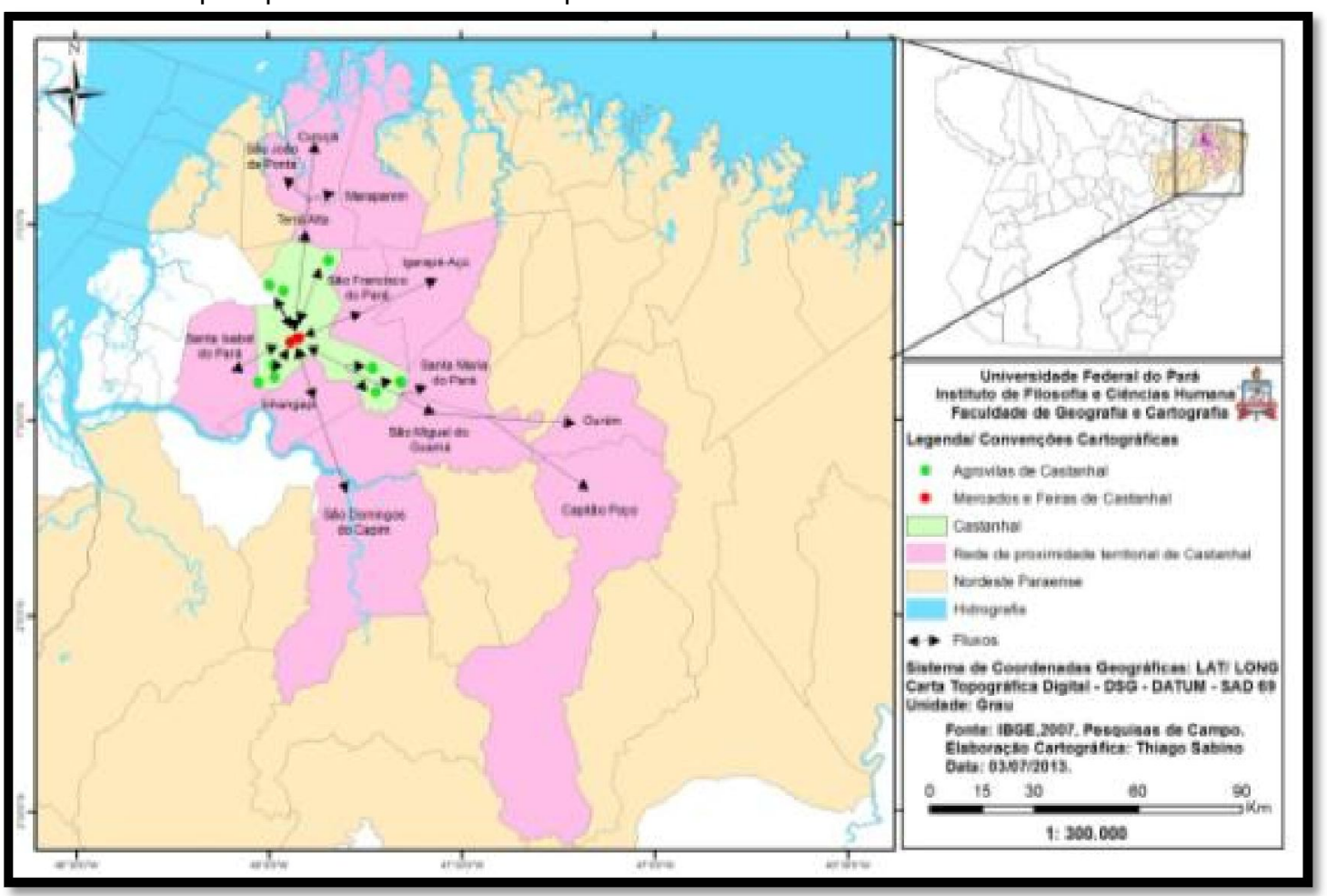

FONTE: Trabalho de campo, outubro de 2012. 
As conexões estabelecidas por Castanhal a partir das demais feiras, mercados e empreendimentos do setor de abastecimento serão aqui tratadas como sendo a rede de proximidade relativa da cidade, por considerar que suas relações envolvem diferentes escalas geográficas, além da regional. Neste sentido, a produção comercializada pelos empreendimentos do setor de abastecimento, pela Feira da CeasaCastanhal, pelo Mercado M unicipal Antônio Barros Maciel e pelo Mercado Central Abadias Bezerra, vêm, além do nordeste paraense e da própria Ceasa de Belém, de diferentes regiões do Brasil, tais como: Bahia, Ceará e Pernambuco (Nordeste); Goiás (Centro-Oeste); e São Paulo (Sudeste), por meio da Ceagesp (Companhia de Entrepostos e Armazéns Gerais de São Paulo), que por sua vez articula os estados do sul do Brasil (figura 07).

FIGURA 07: M apa representando a rede de proximidade relativa de Castanhal

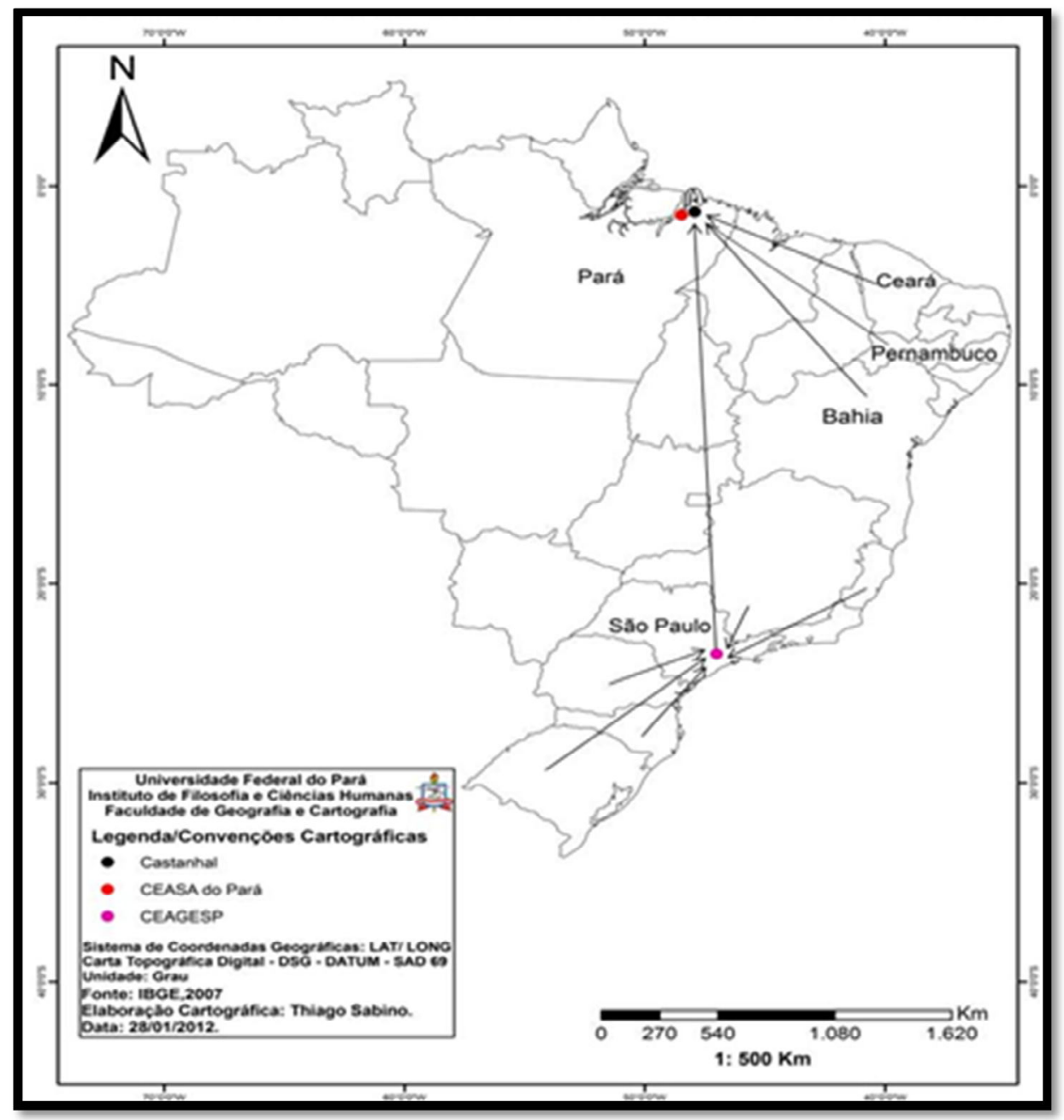

FONTE: Trabalho de campo, outubro de 2012.

Essa produção que chega das diferentes regiões do país até Castanhal é distribuída tanto pelo interior da própria cidade, quanto pelas cidades da sua rede de proximi- 
dade territorial. De acordo com Raimundo Carlos, gerente de uma das empresas de abastecimento que atuam na cidade, na atualidade, a produção chega diretamente até Castanhal, sem passar pela metrópole de Belém, fato que ele considera de suma importância, do mesmo modo ela é distribuída pela região polarizada por Castanhal.

0 que se pode dizer é que a presença de feiras, de empresas de abastecimento e de "agrolojas", ajudam a entender melhor o papel de Castanhal na dinâmica regional, uma vez que mostram que essas atividades pouco ou em nada se articulam com a dispersão metropolitana, reforçando muito mais uma "autonomia relativa" da cidade em relação à metropolização de Belém. Neste sentido, pode-se dizer que na relação campo-cidade, Castanhal tem assumido um papel de uma "cidade do campo", uma cidade que se tornou referência na distribuição de produtos, conhecimentos científicos e tecnologias ligadas ao campo modernizado e não-modernizado da região em que se insere.

\subsection{As elites locais de Castanhal e a centralidade urbana}

Uma das preocupações dessa pesquisa era investigar, mais de perto, a afirmação de Trindade Jr. e Pereira (2007) de que Castanhal, diferentemente de Marabá e Santarém, não apresenta centralidade política, uma vez que tem servido muito mais para reforçar os blocos políticos sediados na metrópole de Belém, o que leva crer que ela é, portanto, uma "área de influência" e um "campo complementar das forças políticas".

Apesar dessa afirmação dos autores, na medida em que foram sendo realizadas as coletas de dados junto aos agentes econômicos da cidade, percebeu-se uma constante na fala dos entrevistados, especialmente, daqueles ligados às elites econômicas locais: uma preocupação de desvincular a trajetória da cidade de Castanhal, vista por eles, em geral, como polo regional do nordeste paraense, daquela de Belém, polo da região metropolitana. Como se verificou:

Existe o incentivo de financiamento, então Castanhal como ela é uma cidade polo, ela atrai muita gente, pela sua estrutura e pelos serviços que ela oferece, por exemplo, as cidades, as cidades que giram em torno de 80 a 100 km de Castanhal, as pessoas não estão mais indo para Belém estudar, porque fica muito caro, o custo de vida da capital é muito maior (...). Então, isso ocorre muito, como a cidade oferece essa estrutura de educação de saúde e a maioria de serviços, tipo, se o cara precisa vir na rede Celpa a central é aqui, a Cosanpa é aqui, a Receita Federal é aqui, a Justiça Federal é aqui, o Fórum da região é aqui, o Eleitoral é aqui. Ai ele já aproveita para ir no dentista, no médico fazer uns exames, tem vários laboratórios de Belém aqui, serviços de Medicina especializada, uma ressonância, tudo tem em Castanhal. Então Castanhal, ela funciona como uma mine capital, então as pessoas passam a investir aqui (Roberto Kataoka Oyama, diretor-presidente da empresa Oyamota do Brasil S/A 26/07/2012). 
Ao se investigar mais de perto a afirmação de que Castanhal não possui centralidade política, chegou-se ao Observatório Social de Castanhal e ao planejamento estratégico de Castanhal. 0 Observatório Social é uma entidade civil que tem como finalidade fiscalizar e acompanhar o poder público (Prefeitura, Câmara Municipal e Secretarias), na aplicação dos recursos para que haja maior transparência e eficiência no uso do dinheiro. Dessa forma, o observatório surgiu em 2010, por iniciativa do empresariado local, principalmente, do Sr. Hélio M elo Filho, presidente da Hiléia Alimentos, que foi quem trouxe a ideia de Maringá (PR), onde o Observatório Social do Brasil foi criado.

Apesar de relativamente recente, esse observatório social tem se desenhado como um espaço privilegiado para reprodução dos interesses das elites locais de Castanhal. Inicialmente, é preciso ressaltar que faz parte de sua diretoria apenas empresas, sindicados e associações eminentemente locais e patronais, dela não fazendo parte grupos econômicos considerados "não locais" (de fora), mesmo aqueles da região metropolitana de Belém, e representantes das classes trabalhadoras da cidade. De acordo com o atual coordenador do Observatório, o Sr. Mozart Mata, a razão para a ausência dessas empresas (de fora) é que elas ainda não entenderam o sentido e o significado da entidade para cidade.

Dentre as principais prioridades de ação da entidade destacam-se: a maior transparência nas contas públicas; a inserção de Castanhal no programa "cidades sustentáveis"; o envio de uma correspondência oficial ao governador do Estado, onde é listada diversas demandas de infraestrutura tanto para Castanhal quanto para a sua região próxima; a implantação do planejamento estratégico de Castanhal. Diante disso, é que se procura questionar se o observatório social não seria, na atualidade, um fórum de discussão política de interesse local e regional.

Como um dos principais resultados da ação do Observatório Social de Castanhal, pode-se citar o Planejamento Estratégico da Prefeitura de Castanhal (2012 -2022), um trabalho financiado pelos sindicatos patronais de Castanhal (SINDCOM, SIM ENE, SIAPA-PA) em parceria com a Prefeitura M unicipal, mas realizado com a consultoria da FIEPA- REDES ${ }^{3}$.

De acordo com a Prefeitura de Castanhal (2012) o planejamento estratégico da cidade não deve ser entendido apenas como um simples planejamento, significando um modo de pensar estrategicamente o desenvolvimento local e regional a partir das forças e fraquezas, bem como das oportunidades e ameaças presentes em sua realidade econômica, política, administrativa, ambiental etc. Dessa forma, afirma que Castanhal está entre as cinco cidades mais importantes do Estado, destacando-se como "metrópole da Região Nordeste do Pará" (CASTANHAL, 2012, p. 9 - grifo nos-

\footnotetext{
${ }^{3}$ Rede de desenvolvimento de Fornecedores (REDES) é um departamento da FIEPA que atua no desenvolvimento de negócios provendo um elo entre as empresas paraenses e os grandes projetos instalados no Estado. A sua atuação traz soluções estratégicas para que os fornecedores atendam as demandas específicas da cadeia de suprimentos de cada M antenedora (PREFEITURA DE CASTANHAL, 2012).
} 
so). Além disso, ressalta sua posição estratégica em relação aos grandes investimentos a serem realizados pelo governo do Estado na região: a) Polo Industrial de Castanhal, a ser instalado a cerca de $5 \mathrm{~km}$ da cidade; b) terminal off-shore do Espadarte, localizado em Curuçá, a 70 km de Castanhal; c) Plataforma Logística do Guamá (PLG), localizada em Inhagapi, acerca de $21 \mathrm{~km}$ da cidade de Castanhal, neste caso, destacam-se também os benefícios de melhorias viárias que irão ocorrer, principalmente, em Castanhal.

Do conteúdo desse planejamento pode-se destacar, para os objetivos deste texto, a matriz geral do ambiente externo em que a cidade de Castanhal está envolvida, pois nela é possível verificar o papel e algumas estratégias de inserção da cidade em relação à região. A localização estratégica é destacada o tempo inteiro no documento como uma força de Castanhal, neste sentido aponta que a concretização do porto espadarte em Curuçá e a ferrovia norte-sul tornará Castanhal um dos principais corredores logísticos como centro de distribuição de cargas. Ainda quanto à localização, destaca a instalação da Plataforma Logística do Guamá (PLG) e do Distrito Industrial de Castanhal, que colocam a cidade nó da integração de grandes empreendimentos: porto espadarte-ferrovia norte-sul-distrito industrial metal-mecânico. Ainda neste sentido, aponta que a cidade deve se tornar uma "excelente alternativa de descentralização para a região metropolitana de Belém" (PREFEITURA DE CASTANHAL, 2012).

Ainda a respeito dos investimentos e das estratégias voltadas para reforçar o papel de Castanhal na rede urbana regional, presentes no planejamento estratégico, podese destacar a implantação de um hospital regional, um aeroporto de cargas, um polo tecnológico e universitário, uma zona de processamento de exportação e a duplicação da rodovia PA-136. Dentre esses investimentos estratégicos, destaca-se a preocupação central de se construir um polo tecnológico na cidade, inclusive com perspectiva de se gastar $\mathrm{R} \$ 100.000,00$ no fortalecimento desse núcleo tecnológico.

Todos esses investimentos acabam por reforçar aquilo que o documento chama de "formação de um polo de abastecimento regional" em Castanhal. Essa é a grande preocupação dos agentes econômicos e políticos da cidade.

Além de articular esse planejamento estratégico para Castanhal, esse grupo conseguiu encaminhar em novembro de 2010, ao recém-eleito governador do Estado, uma carta, apresentando as principais demandas regionais do nordeste paraense pela elite de Castanhal. Assim, destacam-se como demandas:

a) A Possibilidade do Estado realizar infraestrutura do Distrito Industrial de Castanhal e criar incentivos fiscais para que o M unicípio possa atrair novas empresas;

b) Viabilizar em seu Governo a construção de um Hospital Regional em Castanhal, visto que esta Municipalidade já absorve a demanda de pelo menos 25 (vinte e cinco) municípios da região;

c) Asfaltamento da PA 242 que liga a PA 140 (Santo Antônio do Tauá) a Castanhal, km10 da PA 136 - trazendo segurança e desenvolvimento para 
uma região de grande produção agrícola, Agrovila de Iracema, abastecedora de Belém e região;

d) Utilização do campus da UEPA em Castanhal como centro de formação de cursos profissionalizantes e tecnológicos;

e) Possibilidade de nomear para a Secretaria da Agricultura ou EM ATER um membro indicado pela Região Nordeste do Estado;

f) Reestruturação da SECREATARIA DE ESTADO - SAGRI, EMATER, ADEPARÁ, ITERPA E SEM A, de tal forma que o produtor rural possa obter a regularização de suas atividades, bem como, crédito para seus investimentos;

g) Fomentar projetos agroflorestais na região nordeste do estado;

h) Construção de um porto na Agrovila de Pernambuco, Município de Inhangapí, e a pavimentação das vias de acesso, para otimizar o transporte na região;

i) Aplicação da Legislação Estadual existente sobre a exportação de pescado, em especial sobre o processamento mínimo da produção;

j) Instalação de um laboratório para análise e esterilização de pimenta do reino, agregando valor ao produto, bem como, promover 0 alcance de mercados consumidores que tem tal exigência sanitária (CARTA AO GOVERNADOR SIM ÃO JATENE, 10/11/2010).

Em face desses argumentos, principalmente do Observatório Social de Castanhal, organização que esteve à frente da elaboração do planejamento estratégico da cidade e que nos forneceu a carta encaminhada ao governados por representantes do poder local de Castanhal, é que se pode relativizar a afirmação de Trindade Jr. e Pereira (2007), de que Castanhal não tem centralidade política e de que não tem se constituído como um fórum privilegiado para as demandas da região do Nordeste Paraense. Na verdade, esses dados fornecem elementos suficientes para se repensar o papel dessa cidade na dinâmica regional, em que cumpre não apenas um papel técnico, mas também político.

\section{CONCLUSÃO}

Como dito no início o principal objetivo do trabalho foi analisar se as cidades de porte médio que estão territorialmente próximas à metrópole de Belém, especialmente Castanhal, desempenham papel de cidade média, servindo de centro subregional, ou se estão funcionalmente integradas à metrópole de Belém através de redes de proximidade relativa e relacional, de modo a configurar uma metrópole dispersa.

Discutir essa questão não é tarefa das mais fáceis, considerando que Castanhal foi incorporada institucionalmente à Região Metropolitana de Belém, pela Lei Complementar 076, de 28 de dezembro de 2011, e que autores como Alves (2012) a considera como parte da metrópole dispersa, principalmente adotando como variável analítica a produção de espaços de moradia, a produção industrial e o acesso aos serviços básicos em Castanhal. 
De todo modo, os dados obtidos em trabalho de campo foi quem nos autorizou a manter a hipótese de que Castanhal ainda se configura como uma cidade média, um centro sub-regional do nordeste paraense, embora reconhecendo que está passando por um momento de transição sem precedentes para sua configuração futura. Nesta transição, destacam-se, dentre outras, as medidas adotadas pelo governo estadual para inseri-la de fato na Região M etropolitana de Belém, tais como, o projeto da Plataforma Logística do Guamá.

Não se trata de modo algum de achar que ela prescinde da centralidade da metrópole, por isso o uso do termo centro sub-regional. Como se procurou mostrar existe uma forte interação espacial entre Castanhal e Belém, inclusive com a presença da dispersão metropolitana, que tem produzido alguns rebatimentos sobre a primeira cidade. Outrossim, ressaltamos que Castanhal tem um processo de estruturação diferente das cidades do espaço metropolitano, pois não resulta da dispersão da população pobre de Belém e da consequente instalação de assentamentos precários e de conjuntos habitacionais para abrigar essa população. Nem mesmo resulta do processo mais recente de dispersão de assentamentos de média e alta renda. A presença desses assentamentos na cidade está muito mais relacionada à centralidade exercida por Castanhal em relação a uma vasta área do Nordeste Paraense, do que ao caráter disperso da metropolização.

Como centro sub-regional destacamos que Castanhal concentra atividades comerciais e de serviços, como se mostrou ao longo do texto, que nem sempre derivam diretamente da metrópole regional. Por mais que ela tenha sido atingida, recentemente, pela expansão de atividades comerciais e de serviço modernas provenientes da metrópole de Belém, mas também de metrópoles de outras regiões brasileiras, não se pode negar que ainda guarda em seu interior atividades econômicas (feiras, empresas de abastecimento, agrolojas etc.) cujo entendimento se encontra em redes de proximidade territorial e relativa que não estão associadas diretamente aos processos de metropolização.

Do mesmo modo, consideramos importante não perder de vista que os grupos econômicos locais têm buscado se reorganizar face à expansão das atividades econômicas derivadas da metrópole, a fim de se proteger e garantir seus interesses no interior da cidade. O Observatório Social de Castanhal e o planejamento estratégico aqui analisados são uma forma de visualizar essa estratégia das elites locais para manter seus interesses e o seu poder na cidade e na região. Mais do que isso, trata-se de uma forma de obter mais dividendos com o processo de modernização da cidade e da região, uma forma de tomar a dianteira do processo, ao invés de ficar refém das dinâmicas exógenas.

Por fim, é importante dizer que não se quis assumir aqui uma postura dicotômica, mas sim de mostrar que o processo é mais complexo do que se apresenta. Se de um lado, há um movimento da metrópole em direção à cidade média de Castanhal, buscando expandir para ela suas atividades econômicas, reforçando, portanto, um pro- 
cesso de concentração da riqueza; de outro lado, há um movimento econômico e político ocorrendo no interior da cidade de Castanhal, tanto no sentido de fazer frente a expansão econômica da metrópole, como também de garantir a acumulação dos grupos locais por meio dos projetos modernizadores pensados pelo Estado para essa porção da território paraense.

\section{REFERÊNCIAS}

ALVES, Cyntia Santos Daltro. Formas espaciais recentes da urbanização na Amazônia: a dinâmica socioespacial do município de Castanhal em face do processo de dispersão metropolitana. 2012. Dissertação (M estrado em Geografia). IFCH/UFPA, 2012. CAM AGNI, Roberto. Economía urbana. Barcelona: Antonio Bosch, 2005.

CHAVEIRO, Eguimar Felício; ANJOS, Antonio Fernandes dos. A periferia urbana em questão: um estudo socioespacial de sua formação. Boletim Goiano de Geografia, v. 27, n. 2. Goiânia: UFG, 2007.

CORRÊA, Roberto Lobato. Interações espaciais. In: CASTRO, Iná Elias de; CORRÊA, Roberto Lobato; GOM ES, Paulo César da Costa. Explorações geográficas. Rio de Janeiro: Bertrand Brasil, 1997.

DELGADO, Javier. La urbanización difusa, arquetipo territorial de la ciudad-región. Sociológica, año 18, n. 51, 2003.

DIÁRIO OFICIAL DO ESTADO DO PARÁ. Belém: IOEPA, n. 28.116, de 22 de Dezembro de 1995.

Belém: IOEPA, 28 de Dezembro de 2011, CADERNO 2, p. 8.

FERNANDES, Ana Cristina; BITOUN, Jan; ARAÚJO, Tânia Bacelar de. Tipologia das cidades brasileiras. Rio de Janeiro: Letra Capital, Observatório das M etrópoles, 2009.

HAESBAERT, Rogério. Regional-Global: dilemas da região e da regionalização na geografia contemporânea. Rio de Janeiro: Bertrand Brasil, 2010.

IBGE - Instituto Brasileiro de Geografia e Estatística. Censo Demográfico Brasileiro. Rio de Janeiro: IBGE, 2000.

Regiões de Influência das Cidades 2007. Rio de Janeiro: IBGE, 2008.

Censo Demográfico Brasileiro. Rio de Janeiro: IBGE, 2010.

IBGE Cidades [online]. 2015. Disponível em:

http://www.cidades.ibge.gov.br/xtras/home.php. [Acessado em 10/03/2015].

LEANDRO, Leonardo Milanez de Lima; SILVA, Fábio Carlos da. A estrada de ferro de Bragança e a colonização da zona bragantina no estado do Pará. Novos Cadernos NAEA, v. 15, n. 2, 2012.

LENCIONI, Sandra. O processo de metropolização do espaço: uma nova maneira de falar da relação entre metropolização e regionalização. In: SCHIFFER, Sueli (Orga.). Globalização e estrutura urbana. São Paulo: HUCITEC / FAPESP, 2004. 
. Da cidade e sua região à cidade-região. In: SILVA, José Borzacchiello da; LIMA, Luiz Cruz; ELIAS, Denise (Orgs.). Panorama da geografia brasileira I. São Paulo: Annablume, 2006.

. Concentração e centralização das atividades urbanas: uma perspectiva multiescalar. Reflexões a partir do caso de São Paulo. Revista de Geografía Norte Grande, v. 39, p. 7-20, 2008.

. A metamorfose de São Paulo: 0 anúncio de um novo mundo de aglomerações difusas. Revista Paranaense de Desenvolvimento, Curitiba, n.120, p.133-148, jan./jun. 2011.

. Metropolização do espaço: processos e dinâmicas. In: FERREIRA, Álvaro; RUA, João; MARAFON, Glaucio José; SILVA, Augusto César Pinheiro da (Orgs.). Metropolização do espaço: gestão territorial e relações urbano-rurais. Rio de janeiro: Consequência, 2013.

M AGALHÃES, Felipe Nunes Coelho. Da metrópole à cidade-região: na direção de um novo arranjo espacial metropolitano? Revista Brasileira de Estudos Urbanos e Regionais, v. 10, n. 2 / novembro 2008.

PREFEITURA MUNICIPAL DE CASTANHAL. Planejamento Estratégico da Prefeitura M unicipal de Castanhal (2012-2022). Castanhal: PM C, 2012.

SIQUEIRA, José Leôncio Ferreira de. Trilhos: o caminho dos sonhos. Bragança, 2008. SPOSITO, Maria Encarnação Beltrão. Novos conteúdos nas periferias urbanas das cidades médias do Estado de São Paulo, Brasil. Investigaciones Geográficas, Boletín del Instituto de Geografía-UNAM, n. 54, 2004.

. Metropolização do espaço: cidades médias, lógicas econômicas e consumo. In: FERREIRA, Álvaro; RUA, João; M ATTOS, Regina Célia (Orgs.). Desafios da metropolização do espaço. Rio de Janeiro: Consequência, 2015.

TRINDADE JR, Saint-Clair Cordeiro da. A cidade dispersa: os novos espaços de assentamentos em Belém e a reestruturação metropolitana. Tese (Doutorado) - Faculdade de Filosofia, Letras e Ciências Humanas, Universidade de São Paulo, São Paulo, 1998. TRINDADE JR, Saint-Clair Cordeiro da; PEREIRA, J. C. C. Reestruturação da rede urbana e importância das cidades médias na Amazônia oriental. In: SPOSITO, M. E. Cidades médias: espaços em transição. São Paulo: Expressão Popular, 2007.

Artigo recebido em 14 de julho de 2016.

Aprovado em 18 de julho de 2016. 